Review

\title{
Phosphatidylinositol 4,5-bisphosphate in the Control of Membrane Trafficking
}

\author{
Suhua Li1 ${ }^{1, \dagger}$, Chinmoy Ghosh ${ }^{1, \dagger}$, Yanli Xing ${ }^{2, \dagger}$, and Yue Sun ${ }^{1, \square}$ \\ 1. Philips Institute for Oral Health Research, School of Dentistry and Massey Cancer Center, Virginia Commonwealth University, Richmond, VA 23298, USA \\ 2. Department of Otolaryngology, Shanghai Pudong New Area Gongli Hospital, Shanghai, China \\ † These authors contributed equally to this work. \\ $\triangle$ Corresponding author: Yue Sun. Philips Institute for Oral Health Research, School of Dentistry and Massey Cancer Center, Virginia Commonwealth \\ University, Richmond, VA 23298, USA. Email: ysun4@vcu.edu. \\ (C) The author(s). This is an open access article distributed under the terms of the Creative Commons Attribution License (https://creativecommons.org/licenses/by/4.0/). \\ See http://ivyspring.com/terms for full terms and conditions.
}

Received: 2020.06.18; Accepted: 2020.08.14; Published: 2020.08.25

\begin{abstract}
Phosphoinositides are membrane lipids generated by phosphorylation on the inositol head group of phosphatidylinositol. By specifically distributed to distinct subcellular membrane locations, different phosphoinositide species play diverse roles in modulating membrane trafficking. Among the seven known phosphoinositide species, phosphatidylinositol 4,5-bisphosphate $\left(\mathrm{PI}_{4}, 5 \mathrm{P}_{2}\right)$ is the one species most abundant at the plasma membrane. Thus, the $\mathrm{PI} 4,5 \mathrm{P}_{2}$ function in membrane trafficking is first identified in controlling plasma membrane dynamic-related events including endocytosis and exocytosis. However, recent studies indicate that $\mathrm{PI}, 5 \mathrm{P}_{2}$ is also critical in many other membrane trafficking events such as endosomal trafficking, hydrolases sorting to lysosomes, autophagy initiation, and autophagic lysosome reformation. These findings suggest that the role of $\mathrm{PI} 4,5 \mathrm{P}_{2}$ in membrane trafficking is far beyond just plasma membrane. This review will provide a concise synopsis of how $\mathrm{PI} 4,5 \mathrm{P}_{2}$ functions in multiple membrane trafficking events. $\mathrm{PI} 4,5 \mathrm{P}_{2}$, the enzymes responsible for $\mathrm{PI} 4,5 \mathrm{P}_{2}$ production at specific subcellular locations, and distinct $\mathrm{PI} 4,5 \mathrm{P}_{2}$ effector proteins compose a regulation network to control the specific membrane trafficking events.
\end{abstract}

Key words: PI4,5 $\mathrm{P}_{2}$, membrane trafficking, PIPK, endosome, lysosome, autophagy

\section{Introduction}

Membrane trafficking, the process using membrane-bound vesicles as transport intermediaries, controls the flow of proteins and other macromolecules materials between different subcellular compartments $[1,2]$. This process is also critical for the communication between the cell and its environment. Normal membrane trafficking processes are essential for maintaining cellular homeostasis and is critical for regulating fundamental processes such as cell signaling, nutrient uptake, immune responses, membrane turnover, and development [3-5].

Phosphoinositides are membrane-containing phospholipids that play a central role in the modulation of membrane trafficking by controlling the membrane dynamics and vesicular transport. They are differentially phosphorylated at the 3, 4, or 5 positions of their inositol ring. Seven phosphoinositide species have been identified as phosphatidylinositol 3-phosphate (PI3P), phosphatidylinositol 4-phosphate (PI4P), phosphatidylinositol 5-phosphate (PI5P), phosphatidylinositol 3,5-bisphosphate (PI3,5 $\left.\mathrm{P}_{2}\right)$, phosphatidylinositol 4,5-bisphosphate (PI4,5 $\left.\mathrm{P}_{2}\right)$, phosphatidylinositol 3,4-bisphosphate $\left(\mathrm{PI} 3,4 \mathrm{P}_{2}\right)$, and phosphatidylinositol 3,4,5-trisphosphate (PI3,4,5 $\mathrm{P}_{3}$ ) (Figure 1) [6]. Different phosphoinositide species can be rapidly converted to each other by phosphorylation or dephosphorylation via specific lipid kinases or phosphatases. The unique distribution of different phosphoinositides species at specific intracellular membranes makes these molecules uniquely suited to direct specific membrane trafficking events [7]. Some studies indicate that PI3P is accumulated at early endosomes, PI4P at the membrane of Golgi apparatus, $\mathrm{PI} 3,5 \mathrm{P}_{2}$ at 
late endocytic compartments, and PI4, $5 \mathrm{P}_{2}$ at the plasma membrane [7]. PI3P regulates membrane dynamics at early endosomes, phagosomes, and autophagosomes [7]. PI3,5 $\mathrm{P}_{2}$ controls late endosomal dynamics [8, 9]. PI4P is a central regulator of Golgi function [7]. As PI4, $5 \mathrm{P}_{2}$ is enriched at the plasma membrane, the research of $\mathrm{PI} 4,5 \mathrm{P}_{2}$ function in membrane trafficking is first focused on membrane dynamics at the plasma membrane such as endocytosis and exocytosis $[10,11]$. However, recent research works reveal the important roles of PI4,5P $\mathrm{P}_{2}$ in many other essential membrane trafficking events, such as endosome maturation, trafficking between endosome and Golgi, lysosomal sorting, and autophagy [12-15]. This review will provide a snapshot of how PI4,5 $\mathrm{P}_{2}$ pathway controls different membrane trafficking events.

\section{Kinases producing $\mathbf{P I} 4,5 \mathrm{P}_{\mathbf{2}}$}

$\mathrm{PI} 4,5 \mathrm{P}_{2}$ is produced by type I and type II phosphatidylinositol-phosphate kinases (PIPKs) (Figure 1) [16]. Type I PIPKs (PIPKIs) subfamily members preferentially utilize PI4P as the substrate to generate the majority of $\mathrm{PI} 4,5 \mathrm{P}_{2}$ in the cell. Type II PIPKs (PIPKIIs) prefer to synthesize PI4,5P 2 using PI5P as substrate. The cellular PI4P concentration is much higher (at least 20-fold) than those of PI5P [6,
17]. Therefore, the majority of cellular PI4,5P $\mathrm{P}_{2}$ is produced by PIPKIs by phosphorylating PI4P [18]. In addition, a small amount of PI4, $5 \mathrm{P}_{2}$ can also been produced by dephosphorylation of $\mathrm{PI} 3,4,5 \mathrm{P}_{3}$ via the phosphatase and tensin homolog (PTEN) (Figure 1) [19].

Both of the PIPKIs and PIPKIIs subfamilies have three isoforms $\alpha, \beta$ and $\gamma$ [18]. Distinct genes encode each different isoforms. Furthermore, the PIPK genes undergo alternative splicing, which generate multiple splice variants and further confers the diversity of PIPKs [20, 21]. Different PIPK isoforms present unique tissue and subcellular distribution patterns. For example, PIPKIa is mainly found in membrane ruffles and the nucleus, whereas, PIPKI $\beta$ is found to majorly distribute to the perinuclear region [18]. The subcellular distribution of PIPKI $\gamma$ isoforms is highly diverse including cell membrane, focal adhesions, and endosomes, which is due to the existence of multiple PIPKI $\gamma$ alternative splicing variants. In human, at least six PIPKI $\gamma$ splice variants have been identified and

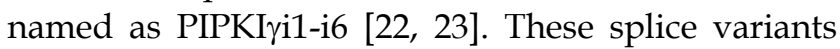
can play distinct function in specific membrane trafficking events. For example, PIPKI $\gamma$ i2 is found at cell adhesions and can mediate the sorting of $\beta 1$ integrin-containing secretory vesicles to plasma membrane by interacting with the exocyst complex

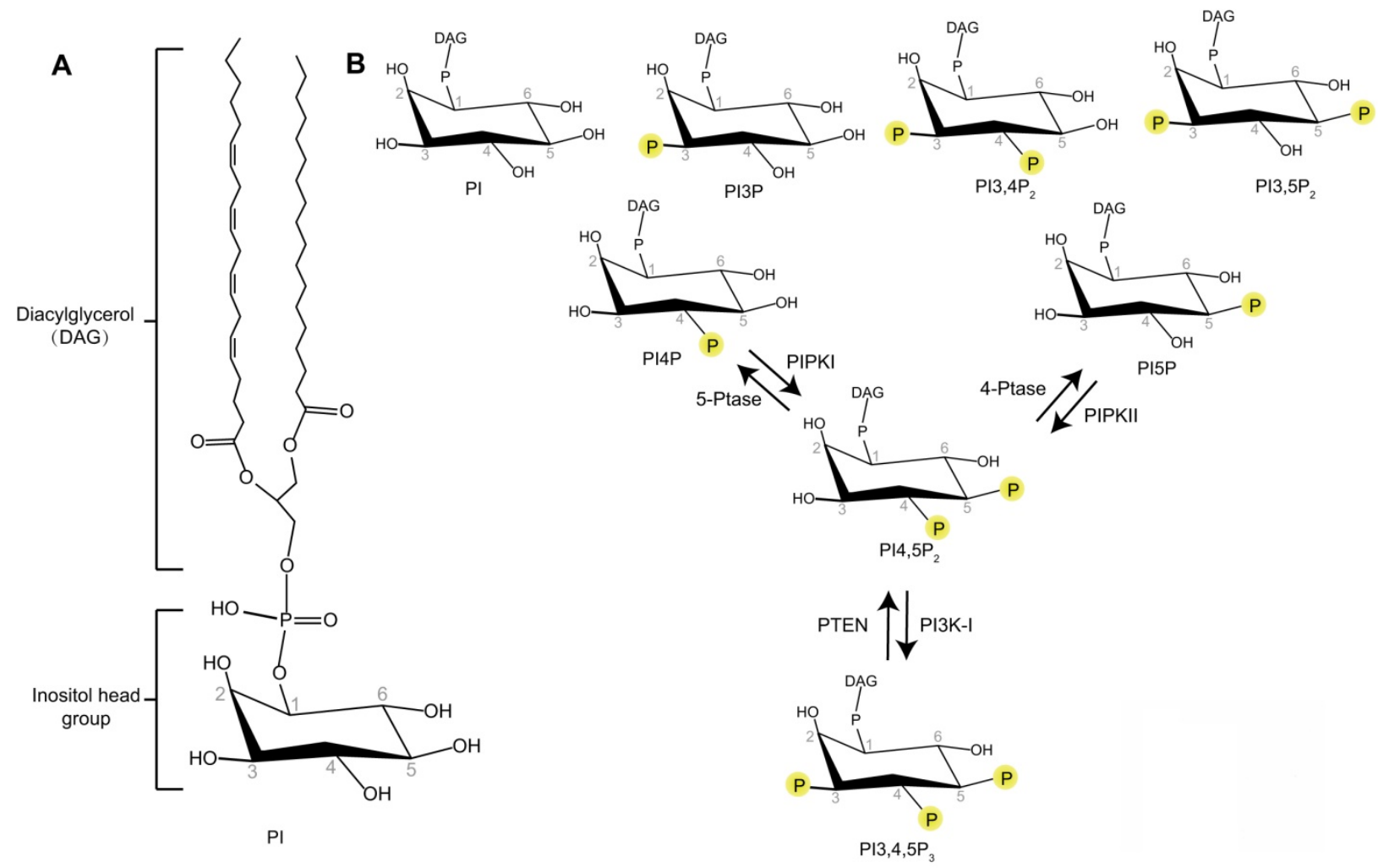

Figure 1. Schematic representation of the phosphoinositides. (A) Phosphatidylinositol (PI) contains an inositol head group connected to a Diacylglycerol (DAG) via a phosphodiester linkage. (B) Phosphate groups can be attached to any permutation of 3-, 4- and 5-hydroxyl groups of the inositol head of PI to produce different phosphoinositides. The interconversion of $\mathrm{PI} 4,5 \mathrm{P}_{2}$ with $\mathrm{PI} 4 \mathrm{P}, \mathrm{PI} \mathrm{P}$, or $\mathrm{PI} 3,4,5 \mathrm{P}_{3}$ by phosphorylation and dephosphorylation are indicated. 
[24]. PIPKI $\gamma$ i5 is located to endosomes and is required for Epidermal Growth Factor Receptor (EGFR) sorting from endosome to lysosome for degradation [12]. These different PIPKI isoforms and splice variants contain a similar kinase core domain with conserved catalytic residues that bind ATP and $\mathrm{Mg}^{2+}$ and the residues to recognize the specific lipid substrate [16]. Outside the kinase core region, the diversity of PIPKI sequences mediate their interaction with specific targeting proteins, which then recruit these kinases to distinct sub-cellular locations to produce PI4,5 $\mathrm{P}_{2}$. Remarkably, many of these targeting proteins are also $\mathrm{PI}, 5 \mathrm{P}_{2}$ effectors, which means they can bind with $\mathrm{PI}, 5 \mathrm{P}_{2}$ and their function is modulated by PI4,5 $\mathrm{P}_{2}$.

Diverse PIPKs, specific PI4,5 $\mathrm{P}_{2}$ effectors, and distinct subcellular PI4,5 $\mathrm{P}_{2}$ pools compose a complicate signaling network to control different membrane trafficking events such as clathrin-mediated endocytosis, exocytosis, endosomal trafficking, hydrolases sorting to lysosomes, and autophagy (Figure 2). PIPKs play a central role in the spatial and temporal control of PI4, $5 \mathrm{P}_{2}$ subcellular production and function. Different PIPKs can be recruited to distinct subcellular locations and produce $\mathrm{PI}, 5 \mathrm{P}_{2}$ in local. Then the subtle change of local PI4,5 $\mathrm{P}_{2}$ levels modulates the function of specific $\mathrm{PI} 4,5 \mathrm{P}_{2}$ effectors to induce diverse biological effects to control specific membrane trafficking events.

\section{Endocytosis}

Endocytosis is a type of active transport that engulfs a wide range of cargo molecules from the cell surface to the interior. This process is essential for cells to the control of signal transduction, to the uptake of nutrients, and to the regulation of plasma membrane composition in response to environmental changes. Although multiple endocytic pathways have been identified in eukaryotic cells, the best characterized pathway is clathrin-mediated endocytosis (CME) [25]. It is the major endocytic route in mammalian cells and responsible for most of the uptake of transmembrane receptors and transporters to regulate cell surface signaling [26, 27]. CME is a multistage process: nucleation of clathrin-coated pits; cargo capture in coated pits; clathrin coat growth to induce curvature and membrane invagination to form a pocket around the target particle; vesicle scission and clathrin uncoating to finally release the particle vesicle to the interior of the cell [28]. PI4,5 $\mathrm{P}_{2}$ pathway plays critical roles in the modulation of CME (Figure $3)$.

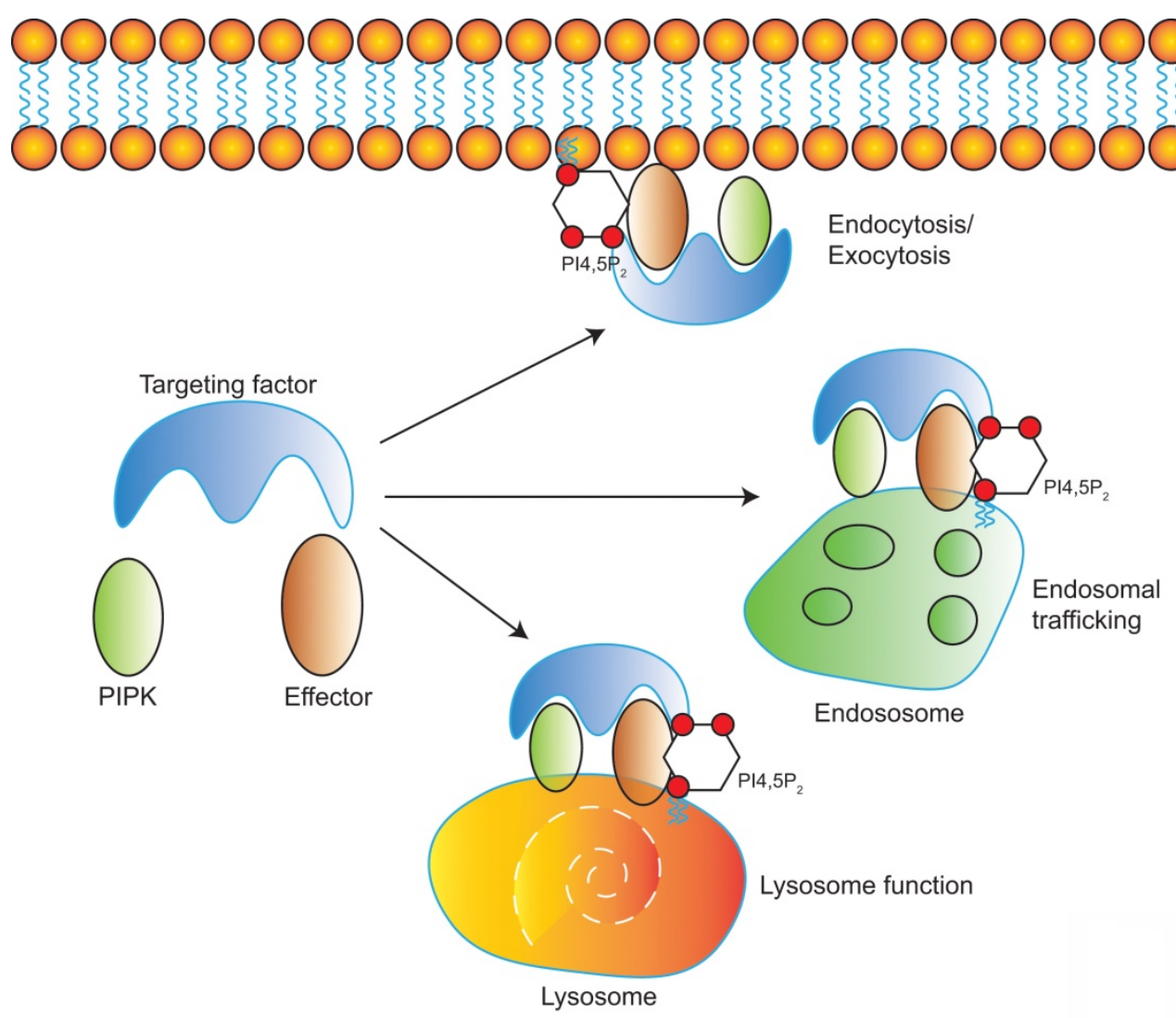

Figure 2. Model of PI4,5P2, PIPKs, and PI4,5P $\mathbf{P}_{2}$-effectors in the regulation of multiple membrane trafficking events. PIPKs can be recruited by different targeting factors to distinct subcellular locations such as plasma membrane, endosomes, and lysosomes. Then the local production of PI4,5P 2 by $\mathrm{PIPKs}$ recruits specific $\mathrm{PI} 4,5 \mathrm{P}_{2}$-effectors to modulate different membrane trafficking events. 


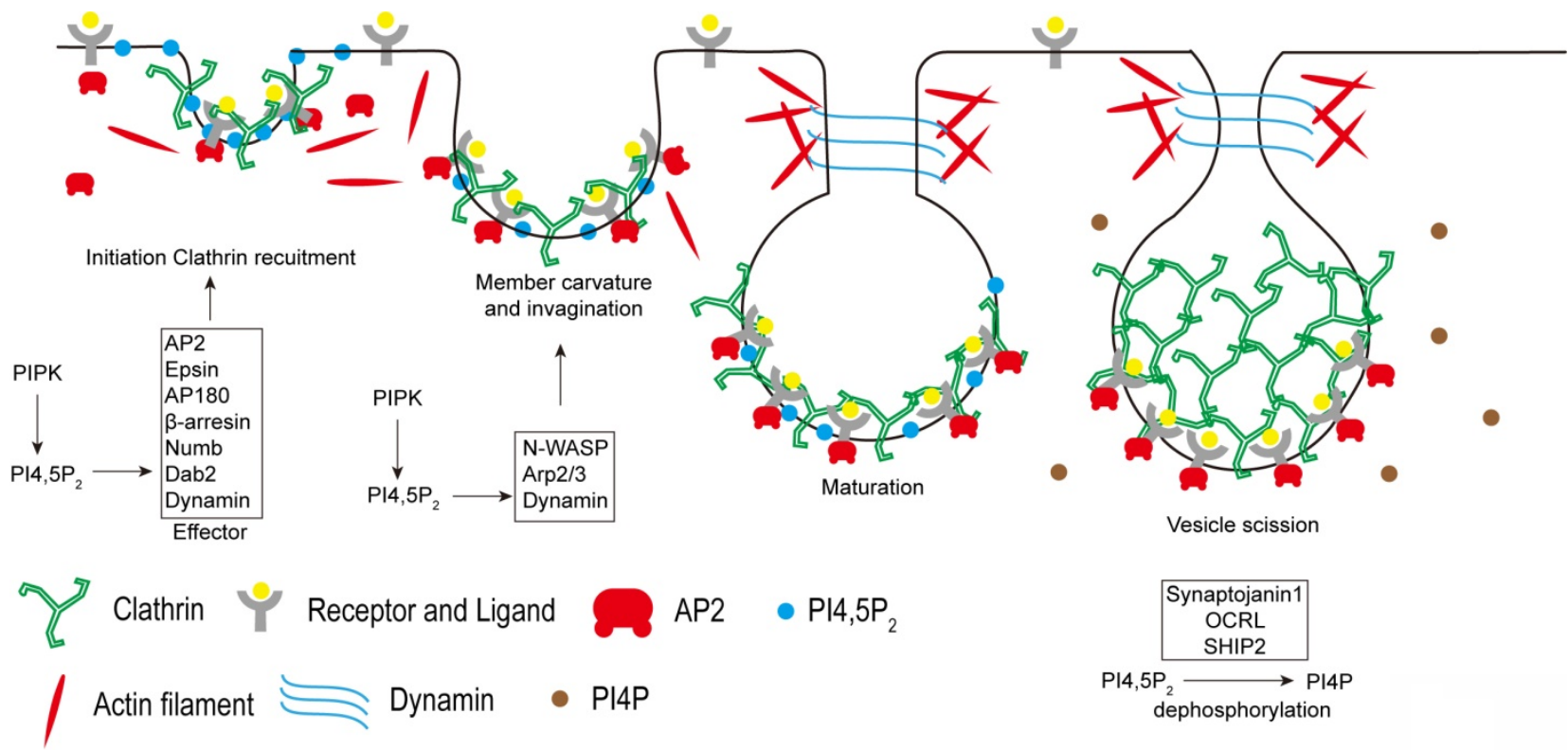

Figure 3. PI4,5 $P_{2}$ in the regulation of Clathrin-mediated endocytosis. PI4,5P2 recruits many clathrin adaptors such as AP2, Epsin, API80, $\beta$-arrestin, Numb, Dab2, and Dynamin to plasma membrane and modulates their functions, which is required for clathrin recruitment to membrane to initiate the formation of clathrin-coated pits. Then by modulating N-WASP, Arp2/3, and Dynamin, P14,5P2 is required for induce membrane curvature, invagination, and maturation of clathrin-coated vesicles. After final scission step, clathrin need to be released from the internalized vesicles. The down-regulation of PI4,5P 2 by phosphoinositide phosphatases synaptojanin 1, OCRL, and SHIP2 at the clathrin-coated vesicles is required for the clathrin releasing.

Being the most abundant phosphoinositide species found at plasma membrane, PI4, $5 \mathrm{P}_{2}$ plays critical role in the control of CME [29]. PI4,5 $\mathrm{P}_{2}$ production is required for the recruitment of clathrin to plasma membrane by modulating the function of clathrin adaptor proteins. Clathrin does not directly bind to membranes. Therefore, the adaptors are required to recruit clathrin and to stabilize its association with the membrane. Many clathrin adaptors, such as the AP2 complex, Epsin, AP180, dynamin, $\beta$-arrestin, Numb, and Dab2 are PI4, $5 \mathrm{P}_{2}$ effectors [30-33]. AP2 complex is one of the key clathrin adaptors composed of two large subunits, aand $\beta 2$-adaptin and two smaller subunits, $\mu 2$ - and o2-adaptin [34]. PI4,5 $\mathrm{P}_{2}$ initially binds with the AP2 a-adaptin subunit, which leads to a conformational change in the $\mu 2$ subunit to expose the binding sites for PI4,5P $\mathrm{P}_{2}$ and the cargo sorting YXX $\Phi$ motifs. Thus, $\mathrm{PI} 4,5 \mathrm{P}_{2}$ strongly enhances the AP2 association with plasma membrane [35]. In turn, AP2 recruits clathrin to the membrane to initiate the formation of clathrin-coated pits. PI4, $5 \mathrm{P}_{2}$ also binds with other AP2 adaptors including epsin, AP180, Dab2, and $\beta$-arresin to further promote the clathrin recruitment to plasma membrane [36]. Besides the roles in clathrin recruitment, $\mathrm{PI} 4,5 \mathrm{P}_{2}$ also coordinates with the ENTH and BAR domains of membrane proteins to regulate membrane deformation to assist in the formation of vesicles $[32,37,38]$. The membrane deformation also requires the coordination of actin cytoskeleton to generate force. PI4,5 $\mathrm{P}_{2}$ can modulate actin cytoskeleton rearrangement via the actin regulating proteins, including N-WASP and Arp2/3 complex $[39,40]$. PI $4,5 \mathrm{P}_{2}$ activates N-WASP by binding to a short polybasic region to release N-WASP auto-inhibition. Therefore, by recruiting and activating N-WASP and Arp2/3 complex, PI4,5P 2 stimulates actin polymerization, which is important for membrane deformation during CME [41]. PI4, $5 \mathrm{P}_{2}$ is also required for the vesicle scission process at the final stages of CME. The GTPase dynamin, a scission factor, can be recruited and activated by PI4, $5 \mathrm{P}_{2}$ at the membrane necks, which is required to force generating events to release the endocytic vesicle from the plasma membrane $[29,42]$.

PIPKIs are the major enzymes responsible for PI4,5P 2 synthesis at plasma membrane. AP2 directly interacts with PIPKI via its $\mu 2$ subunit [43]. The cargo protein binding with $\mu 2$ can further stimulate PIPKI activity to enhance PI4, $5 \mathrm{P}_{2}$ production at the CME sites [43]. Knockdown of PIPKI $\beta$ or PIPKI $\gamma$ isoform inhibits transferrin receptor internalization via CME $[30,44]$, which supports the function of PIPKI in controlling CME. At the synapse, PIPKI $\gamma$ is highly expressed and is critical for maintaining the PI4, $5 \mathrm{P}_{2}$ levels $[45,46]$. Knockout of PIPKI $\gamma$ in mouse dramatically decreases the PI4,5 $\mathrm{P}_{2}$ levels at synapse $[45,46]$. On the contrary, the poly-phosphoinositide phosphatase synaptojanin 1 dephosphorylates PI4,5 $\mathrm{P}_{2}$ to down-regulate it levels at synapse [47]. The disruption of synaptojanin 1 enhances PI4,5 $\mathrm{P}_{2}$ levels and causes an increase of clathrin-coated intermediates accumulated at the endocytic zones [46, 48]. PIPKI $\gamma$ and synaptojanin 1 antagonize each other 
in the regulation of $\mathrm{PI} 4,5 \mathrm{P}_{2}$ levels and in the recruitment of clathrin coats to plasma membranes [46]. Including the mammalian systems, the function of PI4,5P $\mathrm{P}_{2}$ and PIPKs in endocytosis is also reported in many other systems such as in plant and yeast. Phosphatidylinositol-4-phosphate 5-kinase 6 (PIP5K6) is a pollen-enriched Arabidopsis PIPKI that is mainly located to the subapical plasma membrane in pollen tubes [49]. Knockdown of PIP5K6 disrupts the assembly of clathrin onto the apical plasma membrane and impairs endocytosis in pollen tubes [49]. In yeast, Mss4 is the only one kind of PIPKI and it is essential for PI4, $5 \mathrm{P}_{2}$ production and endocytosis [6, 50-52].

At the final step of CME, once the coated vesicles are pinched off from the plasma membrane, the uncoating of clathrin is required for the vesicles to enter subsequent stages of the endocytic trafficking pathway. The recruitment of Rab5 to coated vesicles disrupts AP2-PI4,5P 2 binding [53]. Then the poly-phosphoinositide phosphatase synaptojanin 1

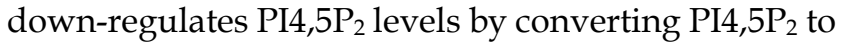
PI4P. Subsequently, auxillin and Hsc70 collaborate to disassemble the clathrin coat [54]. Knockout of Synaptojanin 1 leads to accumulation of clathrin-coated vesicles and delays the vesicle re-availability [55]. Other PI4,5 $\mathrm{P}_{2}$ 5-phosphatases such as oculocerebrorenal syndrome of Lowe protein (OCRL) and Src-homology 2 containing 5-phosphatase 2 (SHIP2) can also be recruited to clathrin-coated vesicles to decrease PI4,5P $\mathrm{P}_{2}$ levels. Loss of these phosphatases impairs CME and causes accumulation of clathrin-coated vesicles [56-58]. Thus, the down-regulation of PI4, $5 \mathrm{P}_{2}$ levels at the clathrin-coated vesicles is a key step for the clathrin uncoating and is required for the recycle of clathrin to form newly coated vesicles.

PIPKIs use PI4P as immediate precursor to make $\mathrm{PI} 4,5 \mathrm{P}_{2}$ by adding phosphorylation at the 5-position of PI4P inositol ring. There are at least two supplying pools of PI4P to support the PI4,5P levels at plasma membrane: one is the PI4P pool directly produced at the plasma membrane, the other is from the Golgi [59]. Specific depletion of PI4P at plasma membrane or Golgi only causes small amount of PI4,5P levels decreasing [59-62]. While depleting PI4P simultaneously at both plasma membrane and Golgi leads to a larger amount decrease of PI4,5 $\mathrm{P}_{2}$ levels at the plasma membrane [59].

Except the CME, there are also some clathrin-independent endocytosis (CIE) pathways are identified including Caveolae-dependent, RhoAregulated, ARF6-regulated, and CDC42-regulated CIE pathways [63]. The molecular mechanisms controlling $\mathrm{CIE}$ are still in the beginning of recognition. Although the reported research works of PI4, $5 \mathrm{P}_{2}$ function in CIE are much less compared with the works in CME, some reports suggest that $\mathrm{PI} 4,5 \mathrm{P}_{2}$ may also play important roles in the regulation of CIE. For example, PI4,5 $\mathrm{P}_{2}$ and its producing kinase PIPKI have been found to modulate ARF6-regulated CIE. Small GTPase Rac1 binding with PIPKI can induce PI4, $5 \mathrm{P}_{2}$ production at ARF6-positive plasma membrane invagination tubules, which is required for ARF6-regulated CIE $[64,65]$. Cortactin and dynamin are PI4,5P 2 -binding proteins and they play critical roles in CIE $[66,67]$. $\mathrm{PI} 4,5 \mathrm{P}_{2}$ may regulate their function in CIE by modulating cortactin- or dynamin-dependent actin assembly and membrane-remodeling. More research are required to further understand the detail function of PI4,5P $\mathrm{P}_{2}$ in CIE.

\section{Endosomal trafficking and endosome maturation}

Endosomes are major protein-sorting stations inside the cells [68]. Once entering the cell, the endocytic vesicles containing cargoes internalized from the plasma membrane will go through multiple rounds of homotypic fusion to form early endosomes $[69,70]$. Cargoes from the Golgi apparatus can also be transported to endosomes [71]. Then the fate of these cargoes is determined by the subsequent endosomal sorting process. From endosomes, these cargoes are sorted to lysosomes for degradation or conversely sorted for retrieval and subsequent recycling to various membrane compartments [68]. In this way, endosomes controls the trafficking and turnover of many important proteins including signaling receptors, lysosomal hydrolase receptors, nutrient transporters, and adhesion molecules [68]. Defects in endosomal sorting are implicated in various human pathologies, such as cancer and neurodegenerative disorders [72-74]. Researches of phosphoinositides function in the control of the endosomal system are first focused on PI3P and $\mathrm{PI}, 5 \mathrm{P}_{2}$ for these two phosphoinositide species are most abundant at the endosomes [75]. The important roles of PI4,5P $\mathrm{P}_{2}$ in this system has only recently been recognized $[12,13,76]$.

PIPKI $\gamma$ i5, an alternative splicing variant of PIPKI $\gamma$, was found to be localized at endosomes [12, 22], which leads to a series of research to explore the possible function of this PI4, $5 \mathrm{P}_{2}$-producing enzyme at the endosomal system. PIPKI $\gamma \mathrm{i} 5$ is required for the sorting of Epidermal Growth Factor Receptor (EGFR) from endosomes to lysosomes for degradation (Figure 4) [12]. EGFR is a plasma membrane containing receptor tyrosine kinase that controls cell growth and differentiation during embryogenesis and adult homeostasis [77]. The EGFR activation levels and the strength of its downstream signaling are tightly 
controlled by endocytosis and the following endosomal trafficking pathway. Upon binding with its agonists such as EGF, EGFR is activated, phosphorylated, ubiquitinated, and then quickly internalized from the plasma membrane [78]. After entering the cell, EGFR is first accumulated at the limiting membrane of early endosomes, where EGFR remains activated and keeps inducing downstream signaling [78]. The ubiquitinated EGFR is recognized by HGF-regulated tyrosine kinase substrate (Hrs), a component of the endosomal sorting complexes required for transport (ESCRT) [79, 80]. By further recruiting other ESCRT components, Hrs mediates the initiation of early endosome limiting membrane invagination, which leads to the sorting of EGFR into intraluminal vesicles (ILVs) [81]. Therefore, EGFR lost connection with its downstream effectors and this blocks EGFR-mediated signaling. Finally, ILVs-containing endosomes fuse with lysosomes and EGFR is then degraded at lysosomes. Loss of PIPKI ij5 does not affect EGFR internalization from plasma membrane, suggesting that PIPKI $\gamma$ i5 is not the major
PI4,5 $\mathrm{P}_{2}$-producing enzyme responsible for endocytosis. Loss of PIPKI $\gamma$ i5 decreases ubiquitinated EGFR interaction with Hrs, which blocks the invagination of early endosome limiting membrane and reduces EGFR sorting into ILVs. Thus, loss of PIPKI $\gamma$ i5 impairs the down-regulation of EGFR signaling. This function of PIPKI $\gamma \mathrm{i} 5$ is mediated by its specific effector protein Sorting Nexin 5 (SNX5). SNX5 is a component of the mammalian retromer complex and is composed of a PX domain and a Bin/Amphiphysin/Rvs (BAR) domain [82]. By associating with Hrs, SNX5 protects Hrs from being ubiquitinated, which can promote the Hrs interaction with EGFR. PIPKI $\gamma$ i5 directly interacts with SNX5, and its product PI4,5P 2 binds to SNX5 PX domain to enhance the SNX5 binding affinity with Hrs. When PIPKI $\gamma \mathrm{i} 5$ is lost, SNX5-Hrs interaction is dramatically decreased [12]. Therefore, PIPKI $\gamma \mathrm{i} 5$, PI4, $5 \mathrm{P}_{2}$, SNX5, and Hrs form a signaling nexus that is required for down-regulating EGFR through the endosomal sorting pathway.

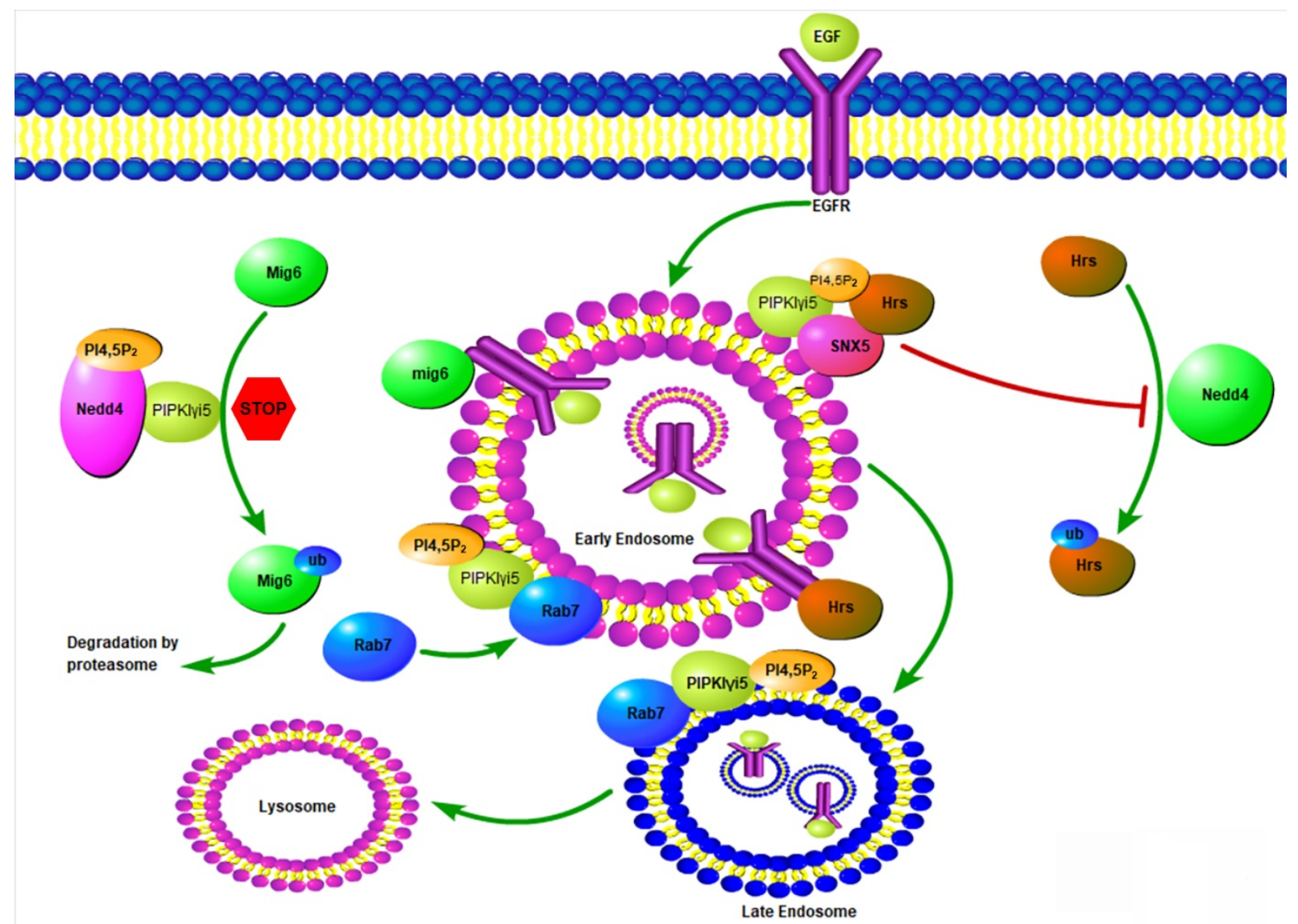

Figure 4. Model of PIPKI $\gamma \mathbf{i 5}$ and PI4,5P $\mathbf{P}_{2}$ in the modulation of EGFR endosomal trafficking. PIPKlyi5, an enzyme producing PI4,5P, controls the endosomal sorting of EGFR by modulating Hrs-EGFR interaction, Mig6 degradation, and Rab7 recruitment to early endosomes. Hrs can recognize ubiquitinated EGFR at the limiting membrane of early endosomes, and then recruit other component of ESCRT complex to initiate the membrane invagination and EGFR sorting into the intraluminal vesicles (ILVs). Hrs can be

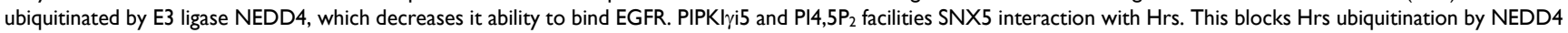
and is required for Hrs interaction with EGFR. Mig6 is another protein that binds to EGFR and is required for the sorting of internalized EGFR to late endosomes and the subsequently sorting to lysosomes for degradation. By interacting with NEDD4, PIPKlyi5 blocks NEDD4-mediated Mig6 ubiquitination to protect Mig6 from being degraded by proteasomes. Rab7 recruitment to early endosomes is a key step for early to late endosome maturation. PIPKI $\gamma$ i5 interacts with Rab7 and is required for Rab7 recruitment to early endosomes. In this way, PIPKI $\gamma$ i5 controls endosome maturation. 
Lysosomal-associated protein transmembrane 4B (LAPTM4B) is another PIPKI $\gamma$ i5 effector that controls EGFR endosomal sorting [83]. LAPTM4B is a four transmembrane protein mainly localized at endosomes and lysosomes [84]. By binding with both Hrs and the E3 ubiquitin ligase NEDD4, LAPTM4B facilitates NEDD4-mediated ubiquitination of Hrs, which blocks Hrs interaction with ubiquitinated EGFR and inhibits EGFR sorting into ILVs. In this way, LAPTM4B impairs EGFR endosomal sorting and disrupts the down-regulation of EGFR signaling [83]. The N-terminus of LAPTM4B contains a polybasic motif (PBM) with a cluster of basic arginine residues that mediates LAPTM4B binding with PI4,5 $\mathrm{P}_{2}$. PIPKI $\gamma$ i5 directly interacts with LAPTM4B and the production of $\mathrm{PI}_{4}, 5 \mathrm{P}_{2}$ further enhances LAPTM4B-PIPKI $\gamma$ i5 interaction and recruits SNX5 to the same complex, which blocks Hrs interaction with LAPTM4B. Therefore, PIPKI $\gamma \mathrm{i} 5$ and SNX5 antagonize the function of LAPTM4B in modulating EGFR endosomal sorting [83].

PIPKI $\gamma$ i5 can also regulate EGFR endosomal sorting and signaling by modulating the expression of Mitogen-inducible Gene 6 (Mig6) [85], a widely expressed tumor suppressor and adaptor protein [86, 87]. Mig6 directly bind to the kinase domain of EGFR to inhibit EGFR activation [86]. Furthermore, Mig6 is required for the sorting of internalized EGFR to late endosomes and the subsequently sorting to lysosomes for degradation [88]. The E3 ubiquitin ligase NEDD4 mediates Mig6 ubiquitination and the subsequent degradation by proteasomes [85]. By directly binding with NEDD4 and producing PI4,5P 2 , PIPKI $i 5$ decreases NEDD4-mediated Mig6 ubiquitination and degradation [85]. Thus, PIPKIri5 promotes the expression levels of Mig6, which contributes to the function of PIPKI $\gamma$ i5 in modulating EGFR endosomal sorting.

The small GTPase Ras-related protein Rab-7a (Rab7a) is a master regulator that controls the organization of endosomal and lysosomal systems $[89,90]$. Rab7a plays a critical role in the maturation of early endosomes into late endosomes [91]. Endocytic membrane cargoes are first sorted to early endosomes, and then the early endosomes need to mature into late endosomes. Subsequently, the late endosomes fuse with lysosomes, and the endocytic cargoes are degraded by the lysosomes. Another small GTPase, Ras-related protein Rab-5a (Rab5a), is mainly located in early endosomes and plays a critical role in the organization of early endosomes $[92,93]$. The early to late endosome maturation requires the replacement of Rab5a by Rab7a [94-96]. PIPKI $i 5$ directly binds with Rab7a to regulate its subcellular location and activation levels [15]. PIPKI $\gamma$ i5 is required for the recruitment of Rab7a to Rab5a-positive early endosomes to initiate the Rab5a to Rab7a conversion. Loss of PIPKI $\gamma$ i5 significantly enhances Rab7a subcellular location at late endosomes and blocks Rab7a recruitment to early endosomes. This suggests that PIPKI $\gamma$ i5 plays fundamental role in modulating endosome maturation. A recent study reported that PI4K2A kinase mediates PI4P production at Rab7a-positive endosomes [97]. PI4P is the substrate of PIPKI $\gamma \mathrm{i} 5$ to produce PI4,5 $\mathrm{P}_{2}$. The acute conversion of endosomal $\mathrm{PI} 4 \mathrm{P}$ to $\mathrm{PI}, 5 \mathrm{P}_{2}$ is required for the release of Rab7a from late endosomes [97]. PIPKI $\gamma \mathrm{i5}$ may be the enzyme responsible for the PI4P to PI4,5 $\mathrm{P}_{2}$ conversion at Rab7a-positive endosomes to control Rab7a subcellular distribution.

Type II Phosphatidylinositol 4-Kinase (type II PI-4K) $\alpha$ and $\beta$ are PI4P-producing enzymes that can localize at endosomes [98]. This indicates that the PIPKI $\gamma$ substrate PI4P can be synthesized at endosomes to support the production of a PI4, $5 \mathrm{P}_{2}$ pool at endosomes. Inhibition of type II PI-4K $\alpha$ kinase activity or knockdown its expression can block the EGFR sorting to late endosomes, a phenotype similar as caused by loss of PIPKI $\gamma$ i5 [99]. The endosomal PI4, $5 \mathrm{P}_{2}$ levels must be tightly controlled and the dysregulation of endosomal PI4, $5 \mathrm{P}_{2}$ can lead to the dysfunction of the endosomes. OCRL is a PI4,5 $\mathrm{P}_{2}$ 5-phosphatase that downregulates PI4,5 $\mathrm{P}_{2}$ levels at endosomes [100]. Loss of OCRL results in the endosomal accumulation of PI4, $5 \mathrm{P}_{2}$ and blocks EGFR sorting from endosome to lysosome for degradation [100]. This indicates that the balance of PI4,5P 2 levels is required for the normal endosomes function.

The endosomal network is morphologically characterized by interconnected vacuolar and tubular elements [101]. The tubular structures of endosomes are thought to mediate the cargo recycling [101, 102]. All three isoforms ( $\alpha, \beta$, and $\gamma$ ) of PIPKI can be found at endosomal tubules and they can produce PI4,5 $\mathrm{P}_{2}$ at tubules [103]. PIPKI collaborates with ACAP1 (ARF GAP with coiled-coil, ankyrin repeat, and pleckstrin homology domains 1) to modulate endosomal tubule formation. ACAP1 has a pleckstrin homology (PH) domain to bind PI4,5P $\mathrm{P}_{2}$ and a Bin/amphiphysin/Rvs (BAR) domain to detect membrane curvature. Coexpression of PIPKI and ACAP1 can strongly induce the endosomal tubules formation [103]. Sorting Nexin family proteins are also important regulators for the formation of endosomal tubular structures [102]. SNX5, SNX6, and SNX9 are three members of Sorting Nexin family proteins that are

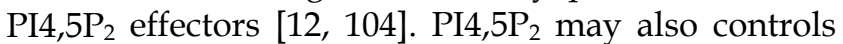
the endosomal tubule formation by modulating these three Sorting Nexins. 


\section{Lysosomes function}

Lysosome is the primary organelle responsible for the degradation of macromolecules including the extracellular materials internalized by endocytosis and intracellular components. Abnormalities in lysosomes are related to various human pathologies such as Huntington's, Parkinson's and Alzheimer's disease $[72,74,105]$. PI4,5 $\mathrm{P}_{2}$ can modulate lysosomes function by regulating the delivery of lysosomal hydrolases to lysosomes and by controlling the lysosome homeostasis [14, 15].

The catabolic capacity of lysosomes is dependent on the lysosomal hydrolases. Around 50 lysosomal hydrolases have been found at lysosomes and they are in charging of the bulk substrates degradation and pro-protein processing [106]. Lysosomal hydrolases are synthesized in the endoplasmic reticulum (ER) and transported through the Golgi complex to the trans-Golgi network (TGN). Endosomes mediates the sorting of lysosomal hydrolases from the TGN to lysosomes. Most lysosomal hydrolases contains a mannose-6-phosphate (M6P) tag in the Golgi complex. Cation-independent Mannose 6-Phosphate Receptors (CI-MPRs) recognize this tag and target the lysosomal hydrolases to the delivery from TGN to endosomes [107]. Ultimately, these hydrolases are transported to lysosomes by endosome-lysosome fusion [108, 109]. CI-MPRs need to be recycled from late endosomes/lysosomes back to the TGN, which is required for CI-MPR to mediate next round of lysosomal hydrolase sorting [110]. PIPKI $\gamma \mathrm{i5}$, the kinase produces PI4,5P , is required for hydrolases sorting to lysosomes by modulating CI-MPR retrograde trafficking from late endosome/lysosome back to TGN. Loss of PIPKI $\gamma$ i5 decreases lysosomal hydrolase delivery to lysosomes and causes functional and morphological change of lysosomes [15]. PIPKI $\gamma$ i5 loss leads to enlarged lysosomes with impaired lysosomal degradative capacity. This function of PIPKI $\gamma$ i5 is mediated by Rab7a and the retromer complex. Rab7a mediates the recruitment of retromer complex to late endosomes, where retromer interacts with CI-MPR to mediate the retro grade trafficking of CI-MPR from late endosomes back to TGN. By interacting with Rab7a and producing $\mathrm{PI}_{4}, 5 \mathrm{P}_{2}$, PIPKI $\gamma \mathrm{i} 5$ promotes the Rab7a-retromer complex interaction, which is required for retromer recruitment to late endosomes. Therefore, loss of PIPKI $i 5$ reduces retromer recruitment to late endosomes and blocks CI-MPR recycling back to TGN. As a result, this decreases hydrolases sorting to lysosomes.

\section{Autophagy}

Autophagy is a self-degradative process whereby the cell digests its cytoplasmic macromolecules within lysosomes [111]. At first, the cytoplasmic compartments are sequestered and engulfed by autophagosomes, then the autophagosomes fuse with lysosomes to form autolysosomes, finally the autophagy substrates are digested in autolysosomes to recycle the materials for sustaining cellular metabolism [112, 113]. Deregulation of autophagy has been found in many human diseases such as cancers, vici syndrome, hereditary spastic paraparesis, lysosomal storage disorders, and Parkinson's disease [111, 114]. PI4,5 $\mathrm{P}_{2}$ and its effectors control multiple critical steps in autophagy (Figure 5).

$\mathrm{PI} 4,5 \mathrm{P}_{2}$ is required for autophagosome biogenesis by controlling the internalization of plasma membrane and delivering the membrane into autophagosome precursors [115]. PI4,5 $\mathrm{P}_{2}$ is partially colocalized with phagophore proteins Atg16L1, Atg12, and Atg5 [115]. Depleting PI4,5 $\mathrm{P}_{2}$ at the plasma membrane by inositol 5-phosphatase causes a block of endocytosis and a decrease of the formation of early autophagic precursors such as Atg12-positive vesicles $[115,116]$. PI $4,5 \mathrm{P}_{2}$ is also required for the membrane delivery from recycling endosomes to autophagosome precursors [117]. SNX18 belongs to the SNX9 family of PX-BAR proteins [118]. It can be recruited to $\mathrm{PI} 4,5 \mathrm{P}_{2}$-containing recycling endosomal membranes via binding with $\mathrm{PI}_{4}, 5 \mathrm{P}_{2}$ [117]. By inducing membrane tabulation, SNX18 plays critical role in the delivery of membrane for phagophore expansion [117].

PIPKI $\gamma$ i5, an endosomal localized PI4,5P producing enzyme, plays important roles in both autophagy initiation and the final autophagy substrates degradation. PIPKI $\gamma$ i5 is required for normal autophagic degradation by modulating the lysosomes function [15]. Loss of PIPKI $\gamma$ i5 leads to autolysosome dysfunction and blocks the autophagy substrates digestion at autolysosomes. Furthermore, it is also reported that PIPKI ji5 and $\mathrm{PI}_{4}, 5 \mathrm{P}_{2}$ can modulate the initiation process of autophagy [13]. The autophagy-related protein 14 (ATG14) and VPS34 (a class III phosphatidylinositol 3-kinase) play key function in the initiation of autophagy. ATG14 contains a C-terminal Barkor/ATG14(L) autophagosome-targeting sequence (BATS) domain that binds with PI4,5P2, which stabilizes the ATG14 interaction with VPS34 and Beclin1. This assembly of ATG14-VPS34-Beclin1 complex is critical for the autophagy initiation. By interacting with ATG14 and producing $\mathrm{PI}_{4}, 5 \mathrm{P}_{2}$, PIPKI $\gamma \mathrm{i5}$ facilitates the ATG14 
complex formation. Loss of PIPKIyi5 causes a loss of ATG14 and Beclin1, which blocks the autophagy initiation [13].

PI4,5 $\mathrm{P}_{2}$ also modulates the autophagosome/ lysosome fusion. Phosphatidylinositol 4-kinase type IIa (PI4KIIa) produces PI4P at lysosomes, which is required for autophagosome/lysosome fusion [119, 120]. The conversion of PI4P to PI4,5 $\mathrm{P}_{2}$ at lysosomes inactivates Rab7a to mediate the release of Rab7a effector PLEKHM1 from lysosomes, which is a critical step for the fusion of lysosome with autophagosome [121]. PIPKI $\gamma$ i5 may be an important enzyme responsible for the PI4P to PI4,5P 2 conversion and Rab7a inactivation at lysosomes. PIPKI 15 can localize to lysosomes. By producing $\mathrm{PI} 4,5 \mathrm{P}_{2}$ and direct interacting with Rab7a, PIPKI $\gamma \mathrm{i} 5$ promotes the Rab7a-retromer interaction at lysosomes [15]. Retromer further recruits TBC1D5, the Rab7a-specific GTPase-activating protein (GAP), to lysosomes [15, 122]. Then TBC1D5 mediates the conversion of active Rab7a (GTP-bound) to inactive Rab7a (GDP-bound).

Autophagic lysosome reformation (ALR) is the process whereby nascent lysosomes are formed from membranes of autolysosomes. ALR is critical for the lysosome homeostasis maintenance. During ALR, tubular structures extrude from autolysosomes, and then small proto-lysosomes pinch off from the reformation tubules. Proto-lysosomes are finally maturated to new functional lysosomes [123]. PI4,5 $\mathrm{P}_{2}$ and clathrin play critical roles in ALR [14]. PIPKI $\beta$, a kinase producing PI4,5 $\mathrm{P}_{2}$, can be recruited to autolysosomes and convert autolysosome-localized PI4P to PI4,5 $\mathrm{P}_{2}$, which causes the recruitment of clathrin adaptor AP2 [14]. Consequently, AP2 recruits clathrin to autolysosomes and induce the membrane curvature and initiation of membrane budding. These processes lead to the reformation tubule extrusion. PIPKIa, another kinase responsible for PI4,5 $\mathrm{P}_{2}$ production, is found to localized at the reformation tubules. By generating PI4,5 $\mathrm{P}_{2}$, PIPKIa recruits clathrin to reformation tubules, which is required for the pinching off of proto-lysosomes [14].

\section{Exocytosis}

Exocytosis is a fundamental membrane trafficking event that release intracellular protein contents such as neurotransmitters, hormones, and cytokines to the cell exterior [124, 125]. It also mediates the polarized delivery of proteins and lipids to specific domains of the plasma membrane [126]. During exocytosis, secretory vesicles undergo different trafficking steps: docking process for recruiting and tethering the vesicles to the plasma membrane, priming process for vesicles maturation to attain fusion-competence, fusion process to fuse with plasma membrane and finally release the vesicle contents [125]. PI4,5P 2 and its effector play important roles in all these steps of exocytosis (Figure 6).
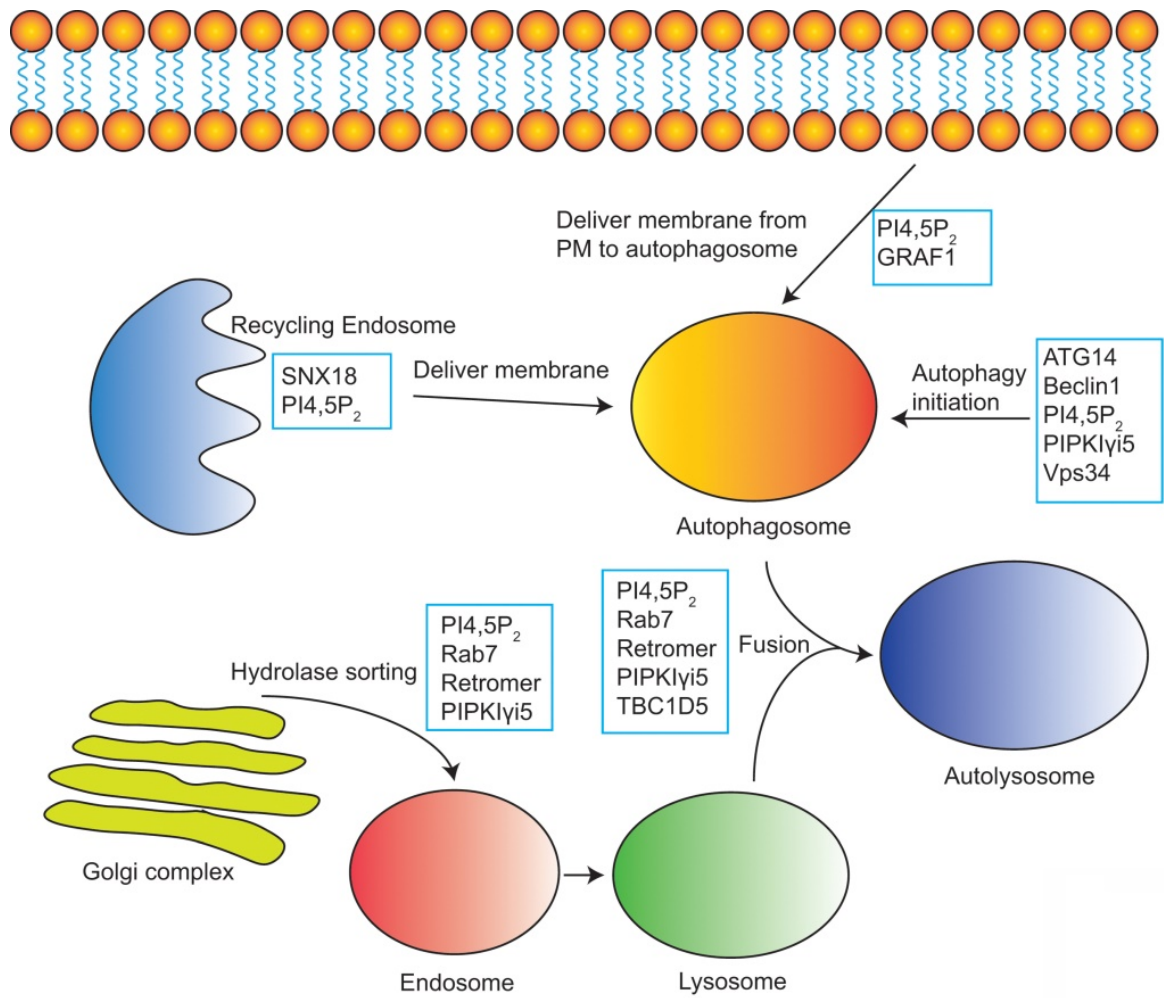

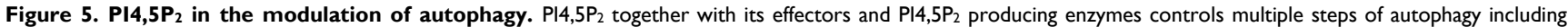
autophagy initiation, membrane delivery from plasma membrane or recycling endosomes to autophagosome, hydrolases sorting to lysosome, and the fusion of autophagosome and lysosome to form autolysosome. 


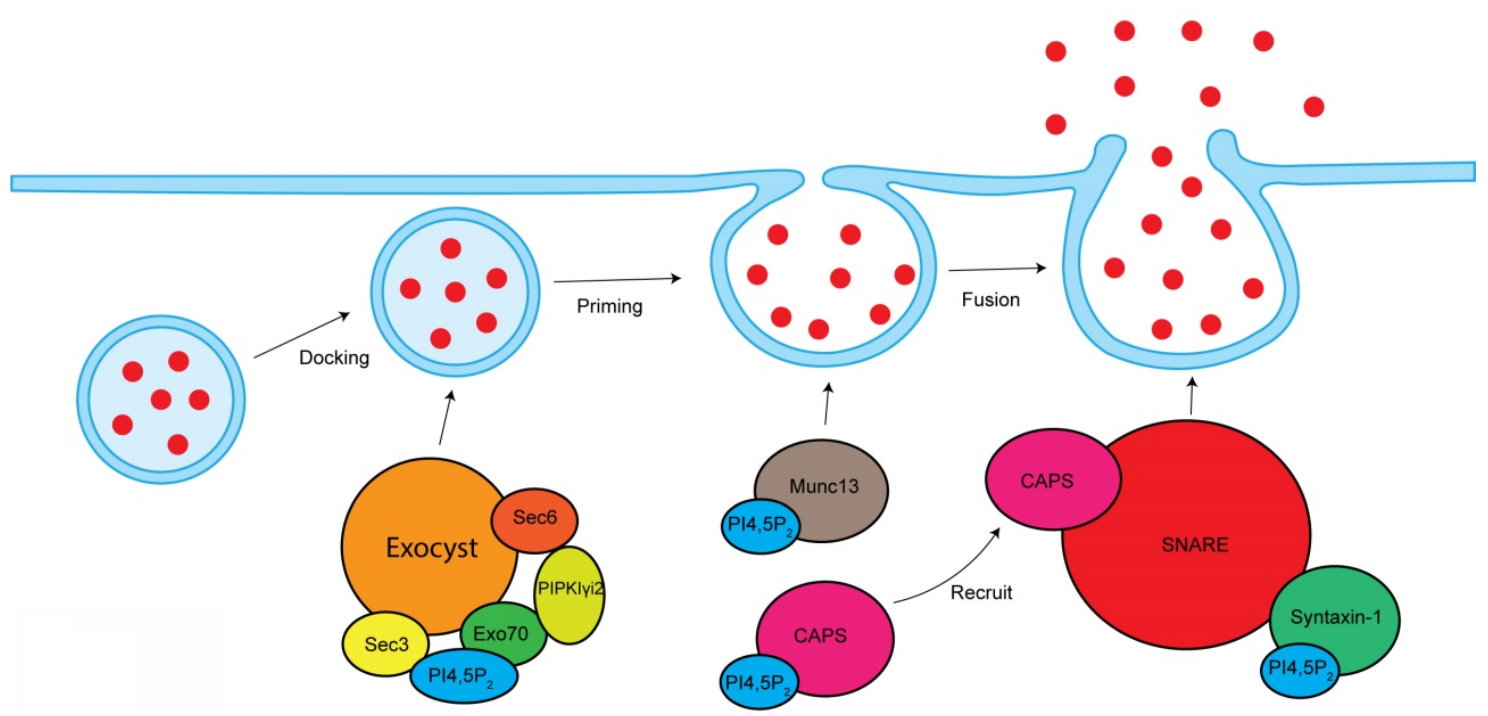

Figure 6. PI4,5 $\mathrm{P}_{2}$ in the modulation of exocytosis. $\mathrm{PI} 4,5 \mathrm{P}_{2}$ is required for exocyst-mediated secretory vesicles sorting to plasma membrane. By interacting and modulating Munc13 and CAPS, PI4,5 $\mathrm{P}_{2}$ modulates vesicle priming. By modulating SNARE complex, Pl4,5P 2 controls vesicles fusion with plasma membrane.

Vesicle exocytosis occurs at PI4,5 $\mathrm{P}_{2}$-rich membrane domains [127]. Locally depleting PI4,5 $\mathrm{P}_{2}$ at vesicle docking sites leads to significantly vesicle undocking from the plasma membrane [128]. Knockout of PIPKI $\gamma$ in mouse causes synaptic transmission defects, a smaller readily releasable pool of synaptic vesicles, and a delay in fusion pore expansion $[45,129]$.

CAPS and Munc13 are two PI4, $5 \mathrm{P}_{2}$ effector proteins that are critical for the vesicle priming. $\mathrm{PI}, 5 \mathrm{P}_{2}$ binds to the $\mathrm{PH}$ domain of CAPS, which is required for CAPS activation to stimulate fusion [130, 131]. PI4, $5 \mathrm{P}_{2}$ present is also required for CAPS to recruit the formation of SNARE complex, a key step to initiate vesicle fusion [132]. The C2B domain of Munc13 binds to PI4,5P 2 in a $\mathrm{Ca}^{2+}$-dependent manner [133]. Munc13 is cytoplasmic, but $\mathrm{Ca}^{2+}$ can stimulate its translocation to $\mathrm{PI} 4,5 \mathrm{P}_{2}$-rich plasma membrane domains, which is required for its activity [131]. SNARE proteins are play critical role in the vesicle fusion [134]. PI4,5P 2 interacts with SNARE proteins and modulates SNARE function. Syntaxin-1, a key component of SNARE proteins, binds to PI4,5 $\mathrm{P}_{2}$, which modulates syntaxin-1 clustering [135]. Depleting PI4, $5 \mathrm{P}_{2}$ at cell membranes by the 5-phosphatase synaptojanin-1 eliminated syntaxin-1 clusters [135], which further supports the function of $\mathrm{PI} 4,5 \mathrm{P}_{2}$ in modulating syntaxin-1 and SNARE proteins. Synaptotagmin is a tandem C2 domain-containing protein that can bind PI4,5P2 [136]. Synaptotagmin can facilitate the inducing of membrane curvature to promote fusion process [136, 137].

The exocyst is an octameric protein complex that mediates the polarized tethering of secretory vesicle to the plasma membrane before the exocytic fusion
[138]. The interaction between exocyst and PI4,5P 2 is required for exocyst to target the secretory vesicles to plasma membrane. Sec3 and Exo70, two subunits of exocyst, directly interacts with $\mathrm{PI}_{4}, 5 \mathrm{P}_{2}$ via their conserved basic residues [139]. The Exo70-PI4,5P 2 interaction is required for the docking and fusion of post-Golgi secretory vesicles [139]. Exo70 mutant with deficiency to bind PI4,5P $\mathrm{P}_{2}$ lost the ability to recruit other exocyst components to the plasma membrane [139]. These reports indicate important role of PI4,5P in mediating exocyst function. PIPKI $\gamma \mathrm{i} 2$, a kinase producing $\mathrm{PI} 4,5 \mathrm{P}_{2}$, directly binds to exocyst subunits sec6 and Exo70 [24]. PIPKIyi2 also interacts with talin [140], a critical protein controlling adhesion turnover. By coordinating exocyst and talin, PIPKI $\gamma \mathrm{i} 2$ facilitates the polarized sorting of integrin to plasma membrane [24].

Exosome is a specific type of secreted extracellular vesicle with the size about $30-200 \mathrm{~nm}$ in diameter [141]. Exosomes can mediate cellular information exchange by transferring RNA, proteins, and lipids contained inside of the exosomes [142]. In this way, exosomes play critical roles in many biological processes including antigen presentation, cellular homeostasis, angiogenesis, and apoptosis [142]. Exosomes are generated from the multivesicular body (MVB, or late endosomes), which are formed by inward budding of the limited membrane of endosomes to produce small intracellular vesicles (ILVs) [143]. ILVs are the precursors of exosomes. The MVB can be sorted towards to plasma membrane, then the fusion with plasma membrane releases ILVs to the extracellular fluid [144]. The released ILVs are so called exosomes. Although very less knowledge is currently known about the PI4,5 $\mathrm{P}_{2}$ function in exosomes, some reports 
suggest that $\mathrm{PI} 4,5 \mathrm{P}_{2}$ may play important roles in exosome production and function. EGFR-containing exosomes have been widely found in cancer microenvironments and can promote cancer metastasis [145, 146]. PIPKI $\gamma \mathrm{i5}$ is localized at endosomes and the production of PI4,5P 2 by PIPKI $\gamma \mathrm{i} 5$ is required for ESCRT complex-mediated EGFR invagination from the endosome limiting membrane to form the ILVs [12]. Therefore, $\mathrm{PI}, 5 \mathrm{P}_{2}$ pathway may affect the packaging of EGFR into the exosome precursors. ARF6 is a critical regulator of exosomes by controlling the budding of endosomes to form ILVs [147]. ARF6 is highly involved in PI4,5 $\mathrm{P}_{2}$ pathway by interacting and activating the PI4, $5 \mathrm{P}_{2}$-producing kinase PIPK [148]. It is possible that ARF6 can modulate $\mathrm{PI} 4,5 \mathrm{P}_{2}$ production at endosomes to regulate ILVs budding. More research is required to further determine the function of PI4, $5 \mathrm{P}_{2}$ pathway in exosome formation and function.

\section{$\mathrm{PI} 4,5 \mathrm{P}_{2}$ pathway dysregulation and disease}

Membrane trafficking dysfunction is highly related to the development of many diseases. As $\mathrm{PI}, 5 \mathrm{P}_{2}$ pathway plays critical roles in membrane trafficking, the dysregulation of $\mathrm{PI} 4,5 \mathrm{P}_{2}$ pathway has been found in diseases such as Lowe syndrome, neuronal disorders and cancer.

Defective of the gene OCRL causes Lowe oculocerebrorenal syndrome, which is characterized by congenital cataracts, central hypotonia, mental retardation, and proximal renal tubular dysfunction [149]. OCRL is an inositol polyphosphate 5-phosphatase that hydrolyzes the 5-phosphate of PI4,5 $\mathrm{P}_{2}$ and converts PI4,5P 2 to PI4P [149]. OCRL is localized at endosomes and controls endosomes function. Loss of OCRL leads to abnormal accumulation of PI4,5 $\mathrm{P}_{2}$ at endosomes and causes defects of multiple membrane receptors recycling [100]. OCRL can also directly bind to clathrin and loss of OCRL leads to endocytic defects [150]. The function of OCRL suggests that the dysregulation of PI4, $5 \mathrm{P}_{2}$ levels at endosomes or clathrin-coated vesicles may contribute to the pathological process of Lowe syndrome.

$\mathrm{PI} 4,5 \mathrm{P}_{2}$ pathway dysregulation is reported in neuronal disorders. PI4,5 $\mathrm{P}_{2}$-producing kinase PIPKI $\gamma$ is highly expressed at neuronal system. Knockout of pan-PIPKI $\gamma$ in mice leads to the synaptic defects and causes the postnatal lethality [45]. The PI4,5 $\mathrm{P}_{2}$ 5-phosphatase Synaptojanin 1 also plays critical roles in the neuronal system. In Synaptojanin 1-knockout mice, PI4,5P $\mathrm{P}_{2}$ levels and clustering of clathrin-coated vesicles are both enhanced in the neurons [47]. PI4,5 $\mathrm{P}_{2}$ may also have a correlation with the development of Alzheimer's disease as the PI4,5 $\mathrm{P}_{2}$ levels are decreased in the Alzheimer-diseased brains [151]. The possible role of $\mathrm{PI}_{4}, 5 \mathrm{P}_{2}$ pathway in Alzheimer's disease still need to be clarified.

By interacting with distinct effectors and localized at specific subcellular locations, different PI4,5 $\mathrm{P}_{2}$-producing kinases may play diverse function in cancer. For example, PIPKI $i 2$ is localized to cell adhesions by interacting with talin. By modulating talin assembly to adhesions and mediating $\beta 1$-integin recycling endosomes trafficking to plasma membrane, PIPKI $\gamma$ i2 promotes cancer cell directional migration and invasion [24, 152]. Therefore, loss of PIPKIyi2 decreases breast cancer migration and invasion [153]. Consistently, decreased PIPKI $\gamma$ i2 expression correlates with better breast cancer patients' prognosis [153]. PIPKI $\gamma$ i5, another splice variant of PIPKI $\gamma$, is localized at endosomes. PIPKI $\gamma \mathrm{i} 5$ interacts with the oncogene LAPTM4B. Expression of LAPTM4B is elevated in many types of cancers and serves as a positive indicator for poor prognosis [154]. LAPTM4B blocks EGFR sorting to lysosome for degradation and thereby promotes EGFR signaling. PIPKI $\gamma$ i5 neutralizes the function of LAPTM4B by blocking EGFR up-regulation [83]. Furthermore, PIPKI $\gamma \mathrm{i} 5$ is critical for the stable expression of Mig6, a tumor suppressor that directly binds to EGFR and inhibits EGFR activation [155]. Therefore, PIPKI $\gamma$ i5 down-regulates EGFR signaling and may function as a tumor suppressor.

\section{Conclusions}

$\mathrm{PI} 4,5 \mathrm{P}_{2}$ plays critical roles in multiple membrane trafficking events happening at diverse subcellular locations including the plasma membrane, endosome, Golgi system, lysosome, autophagosome, and autolysosome. The multifunction of $\mathrm{PI}_{4}, 5 \mathrm{P}_{2}$ is dependent on the diversity of PI4,5 $\mathrm{P}_{2}$-producing enzymes and the PI4, $5 \mathrm{P}_{2}$ effector proteins. Different PIPKs mediate the local production of PI4,5 $\mathrm{P}_{2}$ at distinct subcellular locations, and then specific PI4,5P effectors are recruited to organize the membrane trafficking events.

\section{Acknowledgments}

This work was supported by the American Cancer Society (Research Scholar Grant RSG-17-064-01-TBE). Y.X. is supported by the key disciplines group construction project PWZxq2017-04 of Pudong Health Bureau of Shanghai.

\section{Author Contributions}

S.L., C.G, and Y.X. contributed to conceptualization and writing of the manuscript. Y.S. helped finalized the presented idea and supervised the manuscript. 


\section{Competing Interests}

The authors have declared that no competing interest exists.

\section{References}

1. Cheung AY, de Vries SC. Membrane trafficking: intracellular highways and country roads. Plant Physiol. 2008; 147: 1451-3.

2. Gonzalez L, Jr., Scheller RH. Regulation of membrane trafficking: structural insights from a Rab/effector complex. Cell. 1999; 96: 755-8.

3. Podinovskaia M, Spang A. The Endosomal Network: Mediators and Regulators of Endosome Maturation. Progress in molecular and subcellular biology. 2018; 57: 1-38.

4. Scott CC, Vacca F, Gruenberg J. Endosome maturation, transport and functions. Seminars in cell \& developmental biology. 2014; 31: 2-10.

5. Benarroch EE. Membrane trafficking and transport: overview and neurologic implications. Neurology. 2012; 79: 1288-95.

6. Balla T. Phosphoinositides: tiny lipids with giant impact on cell regulation. Physiol Rev. 2013; 93: 1019-137.

7. Mayinger P. Phosphoinositides and vesicular membrane traffic. Biochim Biophys Acta. 2012; 1821: 1104-13.

8. Schink KO, Raiborg C, Stenmark H. Phosphatidylinositol 3-phosphate, a lipid that regulates membrane dynamics, protein sorting and cell signalling. BioEssays : news and reviews in molecular, cellular and developmental biology. 2013; 35: 900-12

9. Jin N, Lang MJ, Weisman LS. Phosphatidylinositol 3,5-bisphosphate: regulation of cellular events in space and time. Biochemical Society transactions. 2016; 44: 177-84.

10. Jost M, Simpson F, Kavran JM, Lemmon MA, Schmid SL. Phosphatidylinositol-4,5-bisphosphate is required for endocytic coated vesicle formation. Curr Biol. 1998; 8: 1399-402.

11. Barbieri MA, Heath CM, Peters EM, Wells A, Davis JN, Stahl PD. Phosphatidylinositol-4-phosphate 5-kinase-1beta is essential for epidermal growth factor receptor-mediated endocytosis. J Biol Chem. 2001; 276: 47212-6.

12. Sun Y, Hedman AC, Tan X, Schill NJ, Anderson RA. Endosomal type Igamma PIP 5-kinase controls EGF receptor lysosomal sorting. Developmental cell. 2013; 25: 144-55.

13. Tan X, Thapa N, Liao Y, Choi S, Anderson RA. PtdIns(4,5)P2 signaling regulates ATG14 and autophagy. Proceedings of the National Academy of Sciences of the United States of America. 2016; 113: 10896-901.

14. Rong Y, Liu M, Ma L, Du W, Zhang H, Tian Y, et al. Clathrin and phosphatidylinositol-4,5-bisphosphate regulate autophagic lysosome reformation. Nat Cell Biol. 2012; 14: 924-34.

15. Sun M, Luong G, Plastikwala F, Sun Y. Control of Rab7a activity and localization through endosomal type Igamma PIP 5-kinase is required for endosome maturation and lysosome function. FASEB J. 2020; 34: 2730-48.

16. Doughman RL, Firestone AJ, Anderson RA. Phosphatidylinositol phosphate kinases put PI4,5P(2) in its place. J Membr Biol. 2003; 194: 77-89.

17. Hasegawa J, Strunk BS, Weisman LS. PI5P and PI(3,5)P2: Minor, but Essential Phosphoinositides. Cell Struct Funct. 2017; 42: 49-60.

18. Heck JN, Mellman DL, Ling K, Sun Y, Wagoner MP, Schill NJ, et al. A conspicuous connection: structure defines function for the phosphatidylinositol-phosphate kinase family. Crit Rev Biochem Mol Biol. 2007; 42: 15-39.

19. Bunney TD, Katan M. Phosphoinositide signalling in cancer: beyond PI3K and PTEN. Nat Rev Cancer. 2010; 10: 342-52.

20. van den Bout I, Divecha N. PIP5K-driven PtdIns(4,5)P2 synthesis: regulation and cellular functions. J Cell Sci. 2009; 122: 3837-50.

21. Sun Y, Thapa N, Hedman AC, Anderson RA. Phosphatidylinositol 4,5-bisphosphate: targeted production and signaling. Bioessays. 2013; 35: 513-22.

22. Schill NJ, Anderson RA. Two novel phosphatidylinositol-4-phosphate 5-kinase type Igamma splice variants expressed in human cells display distinctive cellular targeting. Biochem J. 2009; 422: 473-82.

23. Xia Y, Irvine RF, Giudici ML. Phosphatidylinositol 4-phosphate 5-kinase Igamma_v6, a new splice variant found in rodents and humans. Biochem Biophys Res Commun. 2011; 411: 416-20.

24. Thapa N, Sun Y, Schramp M, Choi S, Ling K, Anderson RA. Phosphoinositide signaling regulates the exocyst complex and polarized integrin trafficking in directionally migrating cells. Dev Cell. 2012; 22: 116-30.

25. Kaksonen M, Roux A. Mechanisms of clathrin-mediated endocytosis. Nat Rev Mol Cell Biol. 2018; 19: 313-26.

26. Mettlen M, Chen PH, Srinivasan S, Danuser G, Schmid SL. Regulation of Clathrin-Mediated Endocytosis. Annu Rev Biochem. 2018; 87: 871-96.

27. Bitsikas V, Correa IR, Jr., Nichols BJ. Clathrin-independent pathways do not contribute significantly to endocytic flux. Elife. 2014; 3: e03970.

28. Ramanan V, Agrawal NJ, Liu J, Engles S, Toy R, Radhakrishnan R. Systems biology and physical biology of clathrin-mediated endocytosis. Integr Biol (Camb). 2011; 3: 803-15.

29. Zoncu R, Perera RM, Sebastian R, Nakatsu F, Chen H, Balla T, et al. Loss of endocytic clathrin-coated pits upon acute depletion of phosphatidylinositol 4,5-bisphosphate. Proc Natl Acad Sci U S A. 2007; 104: 3793-8.
30. Bairstow SF, Ling K, Su X, Firestone AJ, Carbonara C, Anderson RA. Type Igamma661 phosphatidylinositol phosphate kinase directly interacts with AP2 and regulates endocytosis. J Biol Chem. 2006; 281: 20632-42.

31. Itoh T, Koshiba S, Kigawa T, Kikuchi A, Yokoyama S, Takenawa T. Role of the ENTH domain in phosphatidylinositol-4,5-bisphosphate binding and endocytosis. Science. 2001; 291: 1047-51.

32. Ford MG, Mills IG, Peter BJ, Vallis Y, Praefcke GJ, Evans PR, et al. Curvature of clathrin-coated pits driven by epsin. Nature. 2002; 419: 361-6.

33. Posor Y, Eichhorn-Grunig M, Haucke V. Phosphoinositides in endocytosis. Biochim Biophys Acta. 2015; 1851: 794-804.

34. Ritter B, Blondeau F, Denisov AY, Gehring K, McPherson PS. Molecular mechanisms in clathrin-mediated membrane budding revealed through subcellular proteomics. Biochem Soc Trans. 2004; 32: 769-73.

35. Honing S, Ricotta D, Krauss M, Spate K, Spolaore B, Motley A, et al. Phosphatidylinositol-(4,5)-bisphosphate regulates sorting signal recognition by the clathrin-associated adaptor complex AP2. Mol Cell. 2005; 18: 519-31.

36. Choi S, Thapa N, Tan X, Hedman AC, Anderson RA. PIP kinases define PI4,5P(2)signaling specificity by association with effectors. Biochim Biophys Acta. 2015; 1851: 711-23.

37. Yoon Y, Tong J, Lee PJ, Albanese A, Bhardwaj N, Kallberg M, et al. Molecular basis of the potent membrane-remodeling activity of the epsin $1 \mathrm{~N}$-terminal homology domain. J Biol Chem. 2010; 285: 531-40.

38. Lundmark R, Carlsson SR. Driving membrane curvature in clathrin-dependent and clathrin-independent endocytosis. Semin Cell Dev Biol. 2010; 21: 363-70.

39. Papayannopoulos V, Co C, Prehoda KE, Snapper S, Taunton J, Lim WA. A polybasic motif allows N-WASP to act as a sensor of PIP(2) density. Mol Cell. 2005; 17: 181-91.

40. Higgs HN, Pollard TD. Regulation of actin polymerization by Arp2/3 complex and WASp/Scar proteins. J Biol Chem. 1999; 274: 32531-4.

41. Engqvist-Goldstein AE, Drubin DG. Actin assembly and endocytosis: from yeast to mammals. Annu Rev Cell Dev Biol. 2003; 19: 287-332.

42. Zheng J, Cahill SM, Lemmon MA, Fushman D, Schlessinger J, Cowburn D. Identification of the binding site for acidic phospholipids on the $\mathrm{pH}$ domain of dynamin: implications for stimulation of GTPase activity. J Mol Biol. 1996; 255: 14-21.

43. Krauss M, Kukhtina V, Pechstein A, Haucke V. Stimulation of phosphatidylinositol kinase type I-mediated phosphatidylinositol (4,5)-bisphosphate synthesis by AP-2mu-cargo complexes. Proc Natl Acad Sci U S A. 2006; 103: 11934-9.

44. Padron D, Wang YJ, Yamamoto M, Yin H, Roth MG. Phosphatidylinositol phosphate 5-kinase Ibeta recruits AP-2 to the plasma membrane and regulates rates of constitutive endocytosis. J Cell Biol. 2003; 162: 693-701.

45. Di Paolo G, Moskowitz HS, Gipson K, Wenk MR, Voronov S, Obayashi M, et al. Impaired PtdIns(4,5)P2 synthesis in nerve terminals produces defects in synaptic vesicle trafficking. Nature. 2004; 431: 415-22.

46. Wenk MR, Pellegrini L, Klenchin VA, Di Paolo G, Chang S, Daniell L, et al. PIP kinase Igamma is the major $\mathrm{PI}(4,5) \mathrm{P}(2)$ synthesizing enzyme at the synapse. Neuron. 2001; 32: 79-88.

47. Cremona O, Di Paolo G, Wenk MR, Luthi A, Kim WT, Takei K, et al. Essential role of phosphoinositide metabolism in synaptic vesicle recycling. Cell. 1999; 99. $179-88$

48. Perera RM, Zoncu R, Lucast L, De Camilli P, Toomre D. Two synaptojanin 1 isoforms are recruited to clathrin-coated pits at different stages. Proc Natl Acad Sci US A. 2006; 103: 19332-7.

49. Zhao Y, Yan A, Feijo JA, Furutani M, Takenawa T, Hwang I, et al. Phosphoinositides regulate clathrin-dependent endocytosis at the tip of pollen tubes in Arabidopsis and tobacco. Plant Cell. 2010; 22: 4031-44.

50. Yoshida S, Ohya Y, Nakano A, Anraku Y. Genetic interactions among genes involved in the STT4-PKC1 pathway of Saccharomyces cerevisiae. Mol Gen Genet. 1994; 242: 631-40.

51. Boronenkov IV, Anderson RA. The sequence of phosphatidylinositol-4-phosphate 5-kinase defines a novel family of lipid kinases. J Biol Chem. 1995; 270: 2881-4.

52. Smaczynska-de R II, Costa R, Ayscough KR. Yeast Arf3p modulates plasma membrane PtdIns $(4,5) \mathrm{P} 2$ levels to facilitate endocytosis. Traffic. 2008; 9: 559-73.

53. Semerdjieva S, Shortt B, Maxwell E, Singh S, Fonarev P, Hansen J, et al. Coordinated regulation of AP2 uncoating from clathrin-coated vesicles by rab5 and hRME-6. J Cell Biol. 2008; 183: 499-511.

54. Massol RH, Boll W, Griffin AM, Kirchhausen T. A burst of auxilin recruitment determines the onset of clathrin-coated vesicle uncoating. Proc Natl Acad Sci US A. 2006; 103: 10265-70

55. Mani M, Lee SY, Lucast L, Cremona O, Di Paolo G, De Camilli P, et al. The dual phosphatase activity of synaptojanin1 is required for both efficient synaptic vesicle endocytosis and reavailability at nerve terminals. Neuron. 2007; 56: 1004-18.

56. Nakatsu F, Perera RM, Lucast L, Zoncu R, Domin J, Gertler FB, et al. The inositol 5-phosphatase SHIP2 regulates endocytic clathrin-coated pit dynamics. J Cell Biol. 2010; 190: 307-15.

57. Erdmann KS, Mao Y, McCrea HJ, Zoncu R, Lee S, Paradise S, et al. A role of the Lowe syndrome protein OCRL in early steps of the endocytic pathway. Dev Cell. 2007; 13: 377-90.

58. Wallroth A, Haucke V. Phosphoinositide conversion in endocytosis and the endolysosomal system. J Biol Chem. 2018; 293: 1526-35. 
59. Dickson EJ, Jensen JB, Hille B. Golgi and plasma membrane pools of PI(4)P contribute to plasma membrane PI(4,5)P2 and maintenance of KCNQ2/3 ion channel current. Proc Natl Acad Sci U S A. 2014; 111: E2281-90.

60. Balla A, Kim YJ, Varnai P, Szentpetery Z, Knight Z, Shokat KM, et al. Maintenance of hormone-sensitive phosphoinositide pools in the plasma membrane requires phosphatidylinositol 4-kinase IIIalpha. Mol Biol Cell. 2008; 19: $711-21$.

61. Willars GB, Nahorski SR, Challiss RA. Differential regulation of muscarinic acetylcholine receptor-sensitive polyphosphoinositide pools and consequences for signaling in human neuroblastoma cells. J Biol Chem. 1998; 273: 5037-46.

62. Nakatsu F, Baskin JM, Chung J, Tanner LB, Shui G, Lee SY, et al. PtdIns4P synthesis by PI4KIIIalpha at the plasma membrane and its impact on plasma membrane identity. J Cell Biol. 2012; 199: 1003-16.

63. Mayor S, Pagano RE. Pathways of clathrin-independent endocytosis. Nat Rev Mol Cell Biol. 2007; 8: 603-12.

64. Vidal-Quadras M, Gelabert-Baldrich M, Soriano-Castell D, Llado A, Rentero C, Calvo M, et al. Rac1 and calmodulin interactions modulate dynamics of ARF6-dependent endocytosis. Traffic. 2011; 12: 1879-96.

65. Soriano-Castell D, Chavero A, Rentero C, Bosch M, Vidal-Quadras M, Pol A, et al. ROCK1 is a novel Rac1 effector to regulate tubular endocytic membrane formation during clathrin-independent endocytosis. Sci Rep. 2017; 7: 6866.

66. Sauvonnet N, Dujeancourt A, Dautry-Varsat A. Cortactin and dynamin are required for the clathrin-independent endocytosis of gammac cytokine receptor. J Cell Biol. 2005; 168: 155-63.

67. Grassart A, Meas-Yedid V, Dufour A, Olivo-Marin JC, Dautry-Varsat A, Sauvonnet N. Pak1 phosphorylation enhances cortactin-N-WASP interaction in clathrin-caveolin-independent endocytosis. Traffic. 2010; 11: 1079-91.

68. McNally KE, Cullen PJ. Endosomal Retrieval of Cargo: Retromer Is Not Alone. Trends in cell biology. 2018; 28: 807-22.

69. Salzman $\mathrm{NH}$, Maxfield FR. Intracellular fusion of sequentially formed endocytic compartments. J Cell Biol. 1988; 106: 1083-91.

70. Elkin SR, Lakoduk AM, Schmid SL. Endocytic pathways and endosomal trafficking: a primer. Wien Med Wochenschr. 2016; 166: 196-204.

71. Progida C, Bakke O. Bidirectional traffic between the Golgi and the endosomes - machineries and regulation. J Cell Sci. 2016; 129: 3971-82.

72. Mellman I, Yarden Y. Endocytosis and cancer. Cold Spring Harbor perspectives in biology. 2013; 5: a016949.

73. Tan J, Evin G. Beta-site APP-cleaving enzyme 1 trafficking and Alzheimer's disease pathogenesis. Journal of neurochemistry. 2012; 120: 869-80.

74. Neefjes J, van der Kant R. Stuck in traffic: an emerging theme in diseases of the nervous system. Trends in neurosciences. 2014; 37: 66-76.

75. Clague MJ, Urbe S, de Lartigue J. Phosphoinositides and the endocytic pathway. Exp Cell Res. 2009; 315: 1627-31.

76. Tan X, Sun Y, Thapa N, Liao Y, Hedman AC, Anderson RA. LAPTM4B is a PtdIns(4,5)P2 effector that regulates EGFR signaling, lysosomal sorting, and degradation. The EMBO journal. 2015.

77. Schlessinger J. Ligand-induced, receptor-mediated dimerization and activation of EGF receptor. Cell. 2002; 110: 669-72.

78. Sorkin A, Goh LK. Endocytosis and intracellular trafficking of ErbBs. Exp Cell Res. 2009; 315: 683-96.

79. Henne WM, Buchkovich NJ, Emr SD. The ESCRT pathway. Dev Cell. 2011; 21: $77-91$

80. Eden ER, White IJ, Futter CE. Down-regulation of epidermal growth factor receptor signalling within multivesicular bodies. Biochem Soc Trans. 2009; 37: 173-7.

81. Razi M, Futter CE. Distinct roles for Tsg101 and Hrs in multivesicular body formation and inward vesiculation. Mol Biol Cell. 2006; 17: 3469-83.

82. Wassmer T, Attar N, Harterink M, van Weering JR, Traer CJ, Oakley J, et al. The retromer coat complex coordinates endosomal sorting and dynein-mediated transport, with carrier recognition by the trans-Golgi network. Dev Cell. 2009; 17: 110-22.

83. Tan X, Sun Y, Thapa N, Liao Y, Hedman AC, Anderson RA. LAPTM4B is a PtdIns(4,5)P2 effector that regulates EGFR signaling, lysosomal sorting, and degradation. EMBO J. 2015; 34: 475-90.

84. Shao GZ, Zhou RL, Zhang QY, Zhang Y, Liu JJ, Rui JA, et al. Molecular cloning and characterization of LAPTM4B, a novel gene upregulated in hepatocellular carcinoma. Oncogene. 2003; 22: 5060-9.

85. Sun M, Cai J, Anderson RA, Sun Y. Type I gamma Phosphatidylinositol Phosphate 5-Kinase i5 Controls the Ubiquitination and Degradation of the Tumor Suppressor Mitogen-inducible Gene 6. J Biol Chem. 2016; 291: 21461-73.

86. Zhang X, Pickin KA, Bose R, Jura N, Cole PA, Kuriyan J. Inhibition of the EGF receptor by binding of MIG6 to an activating kinase domain interface. Nature. 2007; 450: 741-4.

87. Frosi Y, Anastasi S, Ballaro C, Varsano G, Castellani L, Maspero E, et al. A two-tiered mechanism of EGFR inhibition by RALT/MIG6 via kinase suppression and receptor degradation. J Cell Biol. 2010; 189: 557-71.

88. Ying $\mathrm{H}$, Zheng $\mathrm{H}$, Scott $\mathrm{K}$, Wiedemeyer $\mathrm{R}$, Yan $\mathrm{H}$, Lim $\mathrm{C}$, et al. Mig- 6 controls EGFR trafficking and suppresses gliomagenesis. Proceedings of the National Academy of Sciences of the United States of America. 2010; 107: 6912-7.

89. Langemeyer L, Frohlich F, Ungermann C. Rab GTPase Function in Endosome and Lysosome Biogenesis. Trends in cell biology. 2018; 28: 957-70.

90. Guerra F, Bucci C. Multiple Roles of the Small GTPase Rab7. Cells. 2016; 5.
91. Wandinger-Ness A, Zerial M. Rab proteins and the compartmentalization of the endosomal system. Cold Spring Harbor perspectives in biology. 2014; 6: a022616.

92. Ullrich $\mathrm{O}$, Horiuchi $\mathrm{H}$, Bucci $\mathrm{C}$, Zerial M. Membrane association of Rab5 mediated by GDP-dissociation inhibitor and accompanied by GDP/GTP exchange. Nature. 1994; 368: 157-60.

93. Jovic M, Sharma M, Rahajeng J, Caplan S. The early endosome: a busy sorting station for proteins at the crossroads. Histology and histopathology. 2010; 25: 99-112.

94. Rink J, Ghigo E, Kalaidzidis Y, Zerial M. Rab conversion as a mechanism of progression from early to late endosomes. Cell. 2005; 122: 735-49.

95. Vonderheit A, Helenius A. Rab7 associates with early endosomes to mediate sorting and transport of Semliki forest virus to late endosomes. PLoS biology. 2005; 3: e233.

96. Poteryaev D, Datta S, Ackema K, Zerial M, Spang A. Identification of the switch in early-to-late endosome transition. Cell. 2010; 141: 497-508.

97. Baba T, Toth DJ, Sengupta N, Kim YJ, Balla T. Phosphatidylinositol 4,5-bisphosphate controls Rab7 and PLEKMH1 membrane cycling during autophagosome-lysosome fusion. The EMBO journal. 2019; 38

98. Balla A, Tuymetova G, Barshishat M, Geiszt M, Balla T. Characterization of type II phosphatidylinositol 4-kinase isoforms reveals association of the enzymes with endosomal vesicular compartments. J Biol Chem. 2002; 277: 20041-50.

99. Minogue S, Waugh MG, De Matteis MA, Stephens DJ, Berditchevski F, Hsuan JJ. Phosphatidylinositol 4-kinase is required for endosomal trafficking and degradation of the EGF receptor. J Cell Sci. 2006; 119: 571-81.

100. Vicinanza M, Di Campli A, Polishchuk E, Santoro M, Di Tullio G, Godi A, et al. OCRL controls trafficking through early endosomes via PtdIns4,5P(2)-dependent regulation of endosomal actin. EMBO J. 2011.

101. Sachse M, Ramm G, Strous G, Klumperman J. Endosomes: multipurpose designs for integrating housekeeping and specialized tasks. Histochem Cell Biol. 2002; 117: 91-104.

102. van Weering JR, Verkade P, Cullen PJ. SNX-BAR-mediated endosome tubulation is co-ordinated with endosome maturation. Traffic. 2012; 13: 94-107.

103. Shinozaki-Narikawa N, Kodama T, Shibasaki Y. Cooperation of phosphoinositides and BAR domain proteins in endosomal tubulation. Traffic. 2006; 7: 1539-50.

104. Lundmark R, Carlsson SR. Sorting nexin 9 participates in clathrin-mediated endocytosis through interactions with the core components. J Biol Chem. 2003; 278: 46772-81

105. Saftig P, Haas A. Turn up the lysosome. Nat Cell Biol. 2016; 18: 1025-7.

106. Saftig P, Klumperman J. Lysosome biogenesis and lysosomal membrane proteins: trafficking meets function. Nat Rev Mol Cell Biol. 2009; 10: 623-35.

107. Braulke T, Bonifacino JS. Sorting of lysosomal proteins. Biochimica et biophysica acta. 2009; 1793: 605-14.

108. Luzio JP, Rous BA, Bright NA, Pryor PR, Mullock BM, Piper RC. Lysosome-endosome fusion and lysosome biogenesis. Journal of cell science. 2000; 113 ( Pt 9): 1515-24.

109. Luzio JP, Hackmann Y, Dieckmann NM, Griffiths GM. The biogenesis of lysosomes and lysosome-related organelles. Cold Spring Harbor perspectives in biology. 2014; 6: a016840.

110. Seaman MN. Cargo-selective endosomal sorting for retrieval to the Golgi requires retromer. The Journal of cell biology. 2004; 165: 111-22.

111. Jiang P, Mizushima N. Autophagy and human diseases. Cell Res. 2014; 24: 69-79.

112. Marino G, Niso-Santano M, Baehrecke EH, Kroemer G. Self-consumption: the interplay of autophagy and apoptosis. Nature reviews Molecular cell biology. 2014; 15: 81-94

113. Kim KH, Lee MS. Autophagy--a key player in cellular and body metabolism. Nature reviews Endocrinology. 2014; 10: 322-37.

114. Levine B, Kroemer G. Autophagy in the pathogenesis of disease. Cell. 2008; 132: $27-42$

115. Moreau K, Ravikumar B, Puri C, Rubinsztein DC. Arf6 promotes autophagosome formation via effects on phosphatidylinositol 4,5-bisphosphate and phospholipase D. J Cell Biol. 2012; 196: 483-96.

116. Ravikumar B, Moreau K, Jahreiss L, Puri C, Rubinsztein DC. Plasma membrane contributes to the formation of pre-autophagosomal structures. Nat Cell Biol. 2010; 12: 747-57.

117. Knaevelsrud H, Soreng K, Raiborg C, Haberg K, Rasmuson F, Brech A, et al. Membrane remodeling by the PX-BAR protein SNX18 promotes autophagosome formation. J Cell Biol. 2013; 202: 331-49.

118. Haberg K, Lundmark R, Carlsson SR. SNX18 is an SNX9 paralog that acts as a membrane tubulator in AP-1-positive endosomal trafficking. J Cell Sci. 2008; 121: $1495-505$

119. Wang H, Sun HQ, Zhu X, Zhang L, Albanesi J, Levine B, et al. GABARAPs regulate PI4P-dependent autophagosome:lysosome fusion. Proc Natl Acad Sci US A. 2015; 112: 7015-20.

120. Ebner M, Koch PA, Haucke V. Phosphoinositides in the control of lysosome function and homeostasis. Biochem Soc Trans. 2019; 47: 1173-85.

121. Baba T, Toth DJ, Sengupta N, Kim YJ, Balla T. Phosphatidylinositol 4,5-bisphosphate controls Rab7 and PLEKHM1 membrane cycling during autophagosome-lysosome fusion. EMBO J. 2019; 38: e100312.

122. Jimenez-Orgaz A, Kvainickas A, Nagele H, Denner J, Eimer S, Dengjel J, et al. Control of RAB7 activity and localization through the retromer-TBC1D5 complex enables RAB7-dependent mitophagy. EMBO J. 2018; 37: 235-54. 
123. Yu L, McPhee CK, Zheng L, Mardones GA, Rong Y, Peng J, et al. Termination of autophagy and reformation of lysosomes regulated by mTOR. Nature. 2010; 465: 942-6.

124. Alabi AA, Tsien RW. Perspectives on kiss-and-run: role in exocytosis, endocytosis, and neurotransmission. Annu Rev Physiol. 2013; 75: 393-422.

125. Wu LG, Hamid E, Shin W, Chiang HC. Exocytosis and endocytosis: modes, functions, and coupling mechanisms. Annu Rev Physiol. 2014; 76: 301-31.

126. Hsu SC, TerBush D, Abraham M, Guo W. The exocyst complex in polarized exocytosis. Int Rev Cytol. 2004; 233: 243-65.

127. Martin TF. $\mathrm{PI}(4,5) \mathrm{P}(2)$-binding effector proteins for vesicle exocytosis. Biochim Biophys Acta. 2015; 1851: 785-93.

128. Ji C, Fan F, Lou X. Vesicle Docking Is a Key Target of Local PI(4,5)P2 Metabolism in the Secretory Pathway of INS-1 Cells. Cell Rep. 2017; 20: 1409-21.

129. Gong LW, Di Paolo G, Diaz E, Cestra G, Diaz ME, Lindau M, et al. Phosphatidylinositol phosphate kinase type I gamma regulates dynamics of large dense-core vesicle fusion. Proc Natl Acad Sci U S A. 2005; 102: 5204-9.

130. Grishanin RN, Kowalchyk JA, Klenchin VA, Ann K, Earles CA, Chapman ER, et al. CAPS acts at a prefusion step in dense-core vesicle exocytosis as a PIP2 binding protein. Neuron. 2004; 43: 551-62.

131. Kabachinski G, Yamaga M, Kielar-Grevstad DM, Bruinsma S, Martin TF. CAPS and Munc13 utilize distinct PIP2-linked mechanisms to promote vesicle exocytosis. Mol Biol Cell. 2014; 25: 508-21.

132. James DJ, Kowalchyk J, Daily N, Petrie M, Martin TF. CAPS drives trans-SNARE complex formation and membrane fusion through syntaxin interactions. Proc Natl Acad Sci U S A. 2009; 106: 17308-13.

133. Shin OH, Lu J, Rhee JS, Tomchick DR, Pang ZP, Wojcik SM, et al. Munc13 C2B domain is an activity-dependent $\mathrm{Ca} 2+$ regulator of synaptic exocytosis. Nat Struct Mol Biol. 2010; 17: 280-8.

134. Han J, Pluhackova K, Bockmann RA. The Multifaceted Role of SNARE Proteins in Membrane Fusion. Front Physiol. 2017; 8: 5

135. van den Bogaart G, Meyenberg K, Risselada HJ, Amin H, Willig KI, Hubrich $\mathrm{BE}$, et al. Membrane protein sequestering by ionic protein-lipid interactions. Nature. 2011; 479: 552-5.

136. Martens S, Kozlov MM, McMahon HT. How synaptotagmin promotes membrane fusion. Science. 2007; 316: 1205-8.

137. Martin TF. Role of $\mathrm{PI}(4,5) \mathrm{P}(2)$ in vesicle exocytosis and membrane fusion. Subcell Biochem. 2012; 59: 111-30.

138. Wu B, Guo W. The Exocyst at a Glance. J Cell Sci. 2015; 128: 2957-64

139. Liu J, Zuo X, Yue P, Guo W. Phosphatidylinositol 4,5-bisphosphate mediates the targeting of the exocyst to the plasma membrane for exocytosis in mammalian cells. Mol Biol Cell. 2007; 18: 4483-92.

140. Ling K, Doughman RL, Firestone AJ, Bunce MW, Anderson RA. Type I gamma phosphatidylinositol phosphate kinase targets and regulates focal adhesions. Nature. 2002; 420: 89-93.

141. Pegtel DM, Gould SJ. Exosomes. Annu Rev Biochem. 2019; 88: 487-514.

142. Gurunathan S, Kang MH, Jeyaraj M, Qasim M, Kim JH. Review of the Isolation, Characterization, Biological Function, and Multifarious Therapeutic Approaches of Exosomes. Cells. 2019; 8.

143. Zhang Y, Liu Y, Liu H, Tang WH. Exosomes: biogenesis, biologic function and clinical potential. Cell Biosci. 2019; 9: 19.

144. Meldolesi J. Exosomes and Ectosomes in Intercellular Communication. Curr Biol. 2018; 28: R435-R44.

145. Zhang H, Deng T, Liu R, Bai M, Zhou L, Wang X, et al. Exosome-delivered EGFR regulates liver microenvironment to promote gastric cancer liver metastasis. Nat Commun. 2017; 8: 15016

146. Zheng H, Zhan Y, Liu S, Lu J, Luo J, Feng J, et al. The roles of tumor-derived exosomes in non-small cell lung cancer and their clinical implications. J Exp Clin Cancer Res. 2018; 37: 226.

147. Ghossoub R, Lembo F, Rubio A, Gaillard CB, Bouchet J, Vitale N, et al. Syntenin-ALIX exosome biogenesis and budding into multivesicular bodies are controlled by ARF6 and PLD2. Nat Commun. 2014; 5: 3477.

148. Marquer C, Tian H, Yi J, Bastien J, Dall'Armi C, Yang-Klingler Y, et al. Arf6 controls retromer traffic and intracellular cholesterol distribution via a phosphoinositide-based mechanism. Nat Commun. 2016; 7: 11919.

149. Prosseda PP, Luo N, Wang B, Alvarado JA, Hu Y, Sun Y. Loss of OCRL increases ciliary $\mathrm{PI}(4,5) \mathrm{P} 2$ in Lowe oculocerebrorenal syndrome. J Cell Sci. 2017; 130: 3447-54.

150. Nandez R, Balkin DM, Messa M, Liang L, Paradise S, Czapla H, et al. A role of OCRL in clathrin-coated pit dynamics and uncoating revealed by studies of Lowe syndrome cells. Elife. 2014; 3: e02975.

151. Stokes CE, Hawthorne JN. Reduced phosphoinositide concentrations in anterior temporal cortex of Alzheimer-diseased brains. J Neurochem. 1987; 48: 1018-21.

152. Sun Y, Ling K, Wagoner MP, Anderson RA. Type I gamma phosphatidylinositol phosphate kinase is required for EGF-stimulated directional cell migration. J Cell Biol. 2007; 178: 297-308.

153. Sun Y, Turbin DA, Ling K, Thapa N, Leung S, Huntsman DG, et al. Type I gamma phosphatidylinositol phosphate kinase modulates invasion and proliferation and its expression correlates with poor prognosis in breast cancer. Breast Cancer Res. 2010; 12: R6.

154. Kasper G, Vogel A, Klaman I, Grone I, Petersen I, Weber B, et al. The human LAPTM4b transcript is upregulated in various types of solid tumours and seems to play a dual functional role during tumour progression. Cancer Lett. 2005; 224: 93-103.
155. Sun M, Cai J, Anderson RA, Sun Y. Type I Gamma Phosphatidylinositol Phosphate 5-kinase i5 Controls the Ubiquitination and Degradation of a Tumor Suppressor Mitogen-Inducible Gene 6. J Biol Chem. 2016. 